\title{
Total Reflection X-ray Fluorescence
}

\author{
Martina Schmeling \\ Loyola University Chicago, mschmel@luc.edu
}

Follow this and additional works at: https://ecommons.luc.edu/chemistry_facpubs

Part of the Biochemistry Commons, and the Chemistry Commons

\section{Recommended Citation}

Schmeling, Martina. Total Reflection X-ray Fluorescence. Physical Sciences Reviews, 4, 7: , 2019. Retrieved from Loyola eCommons, Chemistry: Faculty Publications and Other Works, http://dx.doi.org/ 10.1515/psr-2017-0161

This Article is brought to you for free and open access by the Faculty Publications and Other Works by Department at Loyola eCommons. It has been accepted for inclusion in Chemistry: Faculty Publications and Other Works by an authorized administrator of Loyola eCommons. For more information, please contact ecommons@luc.edu. cc) (i) $\Theta$

This work is licensed under a Creative Commons Attribution-Noncommercial-No Derivative Works 3.0 License. (c) 2019 Walter de Gruyter GmbH, Berlin/Boston. 


\title{
Martina Schmeling ${ }^{1}$
}

\section{Total reflection X-ray fluorescence}

\author{
${ }^{1}$ Loyola University Chicago, Chicago, IL, USA, E-mail: mschmel@luc.edu
}

\begin{abstract}
:
Total reflection X-ray fluorescence (TXRF) spectrometry is a non-destructive and surface sensitive multi-element analytical method based on energy dispersive $X$-ray fluorescence spectrometry with detection limits in the lower picogram range. It utilizes the total reflection of the primary X-ray beam at or below the critical angle of incidence. At this angle, the fluorescence intensity is substantially enhanced for samples present as small granular residue or as thin homogenous layer deposited at the surface of a thick substrate. Generally, two types of application exist: micro- and trace-analysis as well as surface and thin-layer analysis. For micro- and traceanalysis, a small amount of the solid or liquid sample is deposited on an optically flat substrate, typically quartz or polycarbonate. The dried residue is analyzed at a fixed angle setting slightly below the critical angle. Quantification is carried out by means of internal standardization. For surface and thin-layer analysis, the surface of an optically flat substrate is scanned. Variations of the incident angle of the primary X-ray beam provide information about the type and sometimes also the amount of material present at or slightly below the surface of the substrate. Major fields of application are environmental samples, biological tissues, objects of cultural heritage, semiconductors and thin-layered materials and films.
\end{abstract}

Keywords: TXRF, quantitative trace element analysis, non-destructive, surface analysis

DOI: $10.1515 /$ psr-2017-0161

\section{General applications}

- Analysis of biological samples - blood, serum, plasma, bone, teeth and tissues

- Analysis of environmental samples - soil, sediment, water and particulate matter

- Analysis of industrial samples

- Surface analysis of semiconductor wafers for quality control purposes

\section{- Cultural Heritage Samples}

\section{Limitations}

- No information about isotopes and oxidation states

- No light elements with atomic number $Z$ less than 13

- No gas phase samples

- Liquid samples have to be dried

- Micro-analytical method thus sample amount should not exceed several nanogram or $\mathrm{mg} \mathrm{L}^{-1} ; \mathrm{mg} \mathrm{kg}^{-1}$.

- Thin films only, thick samples suffer from matrix effects.

\section{Estimated time for analysis}

- $100 \mathrm{~s}$ to $1 \mathrm{~h}$ depending on concentration of analyte(s) of interest. Longer times are required for very low concentrations (pg L ${ }^{-1}$ or $\mathrm{pg} \mathrm{g}^{-1}$ ). 


\title{
4 Related techniques
}

\author{
- Energy dispersive X-ray fluorescence \\ - Grazing incidence and grazing exit $\mathrm{X}$-ray fluorescence \\ - Inductively coupled - optical emission spectrometry \\ - Graphite furnace atomic absorption spectrometry
}

\section{Introduction}

Total reflection X-ray fluorescence (TXRF) spectrometry is a multi-element micro-analysis method based on conventional energy dispersive X-ray fluorescence. It was first described in 1971 by Yoneda and Horiuchi, who utilized the effect of X-ray total reflection discovered by Compton in 1923 for analysis of small amounts on optically flat surfaces [1]. The first commercial instruments were sold initially for multi-element analysis of various materials in the 1980s, but later also for surface characterization utilizing the angular dependence of Xray fluorescence intensities. TXRF has increased in popularity due to its versatility, ease of use, non-destructive nature and low operation costs. Current instruments are portable, making them suitable for field studies and onsite process control analysis. The method has been applied in almost every field of elemental analysis where low detection limits and multi-element capabilities are required. Its non-destructive feature make TXRF a method of choice for samples, which are precious or need to be available for further characterization with other methods. The ability of probing extremely small sample amounts places TXRF as a superior analytical technique for samples of limited quantity such as some biological fluids and samples of cultural heritage [2-6]. In the semiconductor industry, TXRF is routinely applied to scan wafers for impurities on the surface and in near surface layers [7-9]. In 1986, synchrotron radiation was first used as primary X-ray source instead of an X-ray tube for TXRF improving its detection power by several orders of magnitude and opening up the field for thin-layer analysis [10]. Several synchrotron facilities have now beamlines specifically dedicated to TXRF or can be easily adapted to meet the requirements for TXRF. Examples are BESSY II in Berlin, Germany, Elettra in Trieste, Italy and the Advanced Photon Source at Argonne, Illinois, USA.

Comparable methods with respect to detection power are inductively coupled plasma-mass spectrometry (ICP-MS) and graphite furnace atomic absorption spectrometry (GF-AAS). These two methods have advantages and disadvantages over TXRF. ICP-MS requires significantly larger sample amounts, is destructive, and suffers from matrix interferences for some elements. It also requires much higher operation costs and cannot be made portable. On the other hand, ICP-MS provides information about isotopic masses and has lower detection limits for several elements. GF-AAS is a single-element method and has also to be used stationary in the laboratory setting. For some elements like mercury and arsenic, AAS is superior as the hydride generation method can be used. However, AAS requires often more elaborate sample preparation due to suffering from matrix effects.

\section{Theory}

\subsection{Nature and production of X-rays and the X-ray fluorescence process}

X-rays are highly energetic photons with energies between 0.01 and $100 \mathrm{keV}$ corresponding to wavelengths between $100 \mathrm{~nm}$ and $0.01 \mathrm{~nm}$. They are produced when a cathode filament is heated to very high temperatures to emit electrons. The electrons bombard a metal target serving as anode and can remove electrons from the inner shells of the target material if the energy exceeds the absorption edges of those electrons. Characteristic $X$-rays are produced when electrons from outer shells replace the ejected electrons and emit energy of a specific wavelength as a result. The $\mathrm{X}$-rays exit the tube through a window as primary $\mathrm{X}$-ray beam. In order to obtain $\mathrm{X}$-ray fluorescence, the primary $\mathrm{X}$-rays need to strike a secondary target. If the energy of the primary X-rays exceeds the absorption edges of inner or core electrons in the secondary target, these can be ejected. The produced vacancy can be filled by an electron from a shell further out and the difference in energy between the two shells is emitted as fluorescence radiation. This process continues until the last vacancy is replaced by a free electron. Depending from where the ejected electron originated different series are distinguished [11]:

K-series: K electron was ejected; 1s orbital electron removal 


\section{L-series: L electron was ejected; $2 s, 2 p$ orbital electron removal}

M-series: M electron was ejected; 3s, 3p, 3d orbital electron removal

According to its position in the periodic table, an element can have only $\mathrm{K}$-series, $\mathrm{K}$ and $\mathrm{L}$ series, or $\mathrm{K}$, $\mathrm{L}$ and $\mathrm{M}$ series energies, shown as lines in a spectrum. Elements with atomic number $\mathrm{Z}$ less than 25 show mostly $\mathrm{K}$ lines and elements with atomic numbers higher than 57 show $\mathrm{K}, \mathrm{L}$, and $\mathrm{M}$ lines. The origin of the electron filling the vacant space is shown as Greek letter index after the series letter. The Greek letter $\alpha$ refers to an electron coming from an $\mathrm{L}$ shell, the Greek letter $\beta$ to an electron from an $\mathrm{M}$ shell and so on.

The lines are characteristic for each element and correspond to the minimum energy required to excite electrons to fluorescence. An X-ray spectrum shows the characteristic lines of the anode material used to produce the primary X-ray beam besides the characteristic lines of each element present in an analyte. In addition, it shows some other features: The Bremscontinuum is a spectral distribution within the spectrum and is the result of absorption of electrons within the target material but without electron ejection. In fact, most electron interactions with the target material do not result in the production of X-rays, but rather produce heat. Other spectral features include scattering effects related to collision of electrons within the anode material and within the sample or substrate. Elastic or Rayleigh scattering refers to the process of change in the direction of the electron with no net energy loss, whereas inelastic Compton and Raman scattering are the consequence of a change in the direction of electron with net energy loss. Both Raman and Rayleigh scattering can be coherent or non-coherent. Compton scattering is always incoherent [11].

\subsection{Refraction and reflection of X-rays}

Refraction or reflection of an X-ray beam occurs when it strikes the surface of a solid medium under a certain angle $\varphi$. For two media 1 and 2 having refractive indices $n_{1}$ and $n_{2}$, the following relationship for the incident angle $\varphi$ is found according to Snell's law (1):

$$
n_{1} \cos \varphi_{1}=n_{2} \cos \varphi_{2}
$$

If absorption of photons by the material has to be considered, the refractive index $n$ has to be extended and is made up of a real part $\delta$ and an imaginary part i $\beta$. The real part describes the decrement of dispersion and the imaginary part the absorption within the medium:

$$
n=1-\delta-i \beta
$$

For X-rays, both $\delta$ and $\beta$ are zero in vacuum or air, but somewhat positive for solids. As a result, any solid medium has a refractive index $n$ smaller than unity, and thus is optically less dense than air (vacuum) and the refracted beam will be deflected toward the medium boundary. At very small incident angles, the refracted beam exits the surface. The exact angle at which that happens is called the critical angle $\varphi_{c}$. When the angle of the primary beam $\varphi_{1}$ is smaller or equal $\varphi_{c}$ total external reflection occurs. Using Snell's law (1), the critical angle $\varphi_{c}$ can be calculated for a medium of known composition by

$$
\varphi_{c}=\frac{10^{-5}}{E} \sqrt{C_{m}}
$$

with $E$ being the energy of the primary $X$-rays in $\mathrm{keV}$ and $C_{\mathrm{m}}$ being a material constant taking the atomic number $Z$, atomic mass $m$ and density $p$ of the material into account.

At the critical angle, the reflectivity $R$ rises to almost $100 \%$ and the penetration depth $z_{\mathrm{p}}$ of the primary beam into the medium becomes only a few nanometer. Reflectivity $R$ can be calculated for any material using the Fresnel expressions (4) with $\varphi_{1}$ and $\varphi_{2}$ being the glancing angle of the incoming beam in medium 1 and medium 2, respectively,

$$
R=\left|\frac{\varphi_{1}-\varphi_{2}}{\varphi_{1}+\varphi_{2}}\right|^{2}
$$

Penetration depth $z_{\mathrm{p}}$ refers to the depth at which the intensity of the primary beam is reduced to $\mathrm{e}^{-1}$ or $37 \%$ of its initial value. It is normal to the medium boundary and can be calculated as 


$$
z_{p}=\frac{\lambda}{4 \pi} \frac{1}{\varphi_{i a}}
$$

with $\varphi_{\text {ia }}$ being the absorption component at a given angle.

For incident angles $\varphi_{i}$ larger than the critical angle the penetration depth of the primary beam increases from about $0.1 \mu \mathrm{m}$ to about $10 \mu \mathrm{m}$, whereas it remains low below the critical angle. The very low penetration depth of the primary beam at and below the critical angle is responsible for the low detection limits and high sensitivity of TXRF. Material deposited on the surface or embedded within the uppermost layers of the solid substrate experience a very low background signal in comparison to conventional X-ray fluorescence due to the shallow penetration depth of the primary X-rays [12, 13].

Table 1 shows a selection of critical angles, reflectivity and penetration depth of some common materials used as substrates in total reflection X-ray analysis. The data are calculated for a primary X-ray energy of $17.44 \mathrm{keV}$, corresponding to Mo K excitation. It can be seen that the reflectivity at the critical angle for materials composed of light elements is high, but decreases with increasing atomic number $Z$. The reverse is true for penetration depth $z_{\mathrm{p}}$, which is less for heavier elements than for lighter elements. For instance, quartz $\left.(\mathrm{SiO})\right)$ has a reflectivity of $85.5 \%$ and a penetration depth of $83 \mathrm{~nm}$ at the critical angle, whereas gold has a reflectivity of only $38.7 \%$ and a penetration depth of $5.0 \mathrm{~nm}$ at the critical angle. For the heavier elements, absorption effects become more prominent and affect reflectivity and penetration depth.

Table 1: Critical angles $\varphi_{c}$, reflectivity $R$ and penetration depth $z_{p}$ at the critical angle for selected materials calculated for $17.44 \mathrm{keV}(\mathrm{Mo} \mathrm{K} \alpha)$ primary X-ray beam energy.

\begin{tabular}{llll}
\hline Material & $\boldsymbol{\varphi}_{\mathbf{c}}\left[^{\circ}\right]$ & $\mathbf{R}[\%]$ & $\mathbf{z}_{\mathbf{p}}[\mathbf{n m}]$ \\
\hline Plexiglass & 0.076 & 93.2 & 241 \\
Glassy carbon & 0.08 & 93.9 & 255 \\
Boron nitride & 0.1 & 93.3 & 188 \\
Quartz glass & 0.1 & 85.5 & 83 \\
Aluminum & 0.11 & 82.9 & 64 \\
Silicon & 0.1 & 81.5 & 62 \\
Copper & 0.19 & 56.1 & 11.5 \\
Germanium & 0.15 & 51.2 & 13.1 \\
Gallium arsenide & 0.15 & 51.1 & 13.0 \\
Gold & 0.26 & 38.7 & 5.0 \\
\hline
\end{tabular}

As eq. 3 shows, the critical angle is a function of energy of incoming or primary X-rays and will change when the anode material changes. For example, the critical angle for quartz glass and Mo K (17.44 keV) as primary beam is 0.1 degree. When $\mathrm{Cu} \mathrm{K}(8.05 \mathrm{keV})$ is used as primary beam, the critical angle increases to 0.22 degree due to the lower energy of cupper K radiation.

\subsection{X-ray standing waves XSW}

TXRF is associated with a standing wave field formed as a result of interference between primary and reflected X-ray beam near or at the critical angle. For a thick flat substrate, superposition of two or more coherent and monochromatic X-ray beams yields a triangular standing wave field with minima (nodes) and maxima (antinodes) in front of the substrate. The difference between minimum and maximum varies with incident angle and is most pronounced at the critical angle. Figure 1 shows schematically such a standing wave field in front of a thick flat substrate. For a reflectivity of almost $100 \%$, the amplitude of incoming and total reflected wave can be subtracted to zero (nodes) or added to a maximum value (antinodes). Minima and maxima are alternating with a period of $d_{\min / \max }=(\lambda / 2) \varphi^{-1}$. Here, $\lambda$ is the wavelength and $\varphi$ the angle of the primary $X$-ray beam. When a sample is placed on top of the thick flat substrate it is subjected to this standing wave field and excited to fluorescence proportional to the wave field intensity. To obtain maximum fluorescence, the sample should be present well inside the standing wave field and should be granular or uneven to prevent total reflection inside the sample. Samples should be small and thin as for too large and too thick samples absorption effects become more prominent. The optimal thickness for a granular sample is $100 \mathrm{~nm}$. 


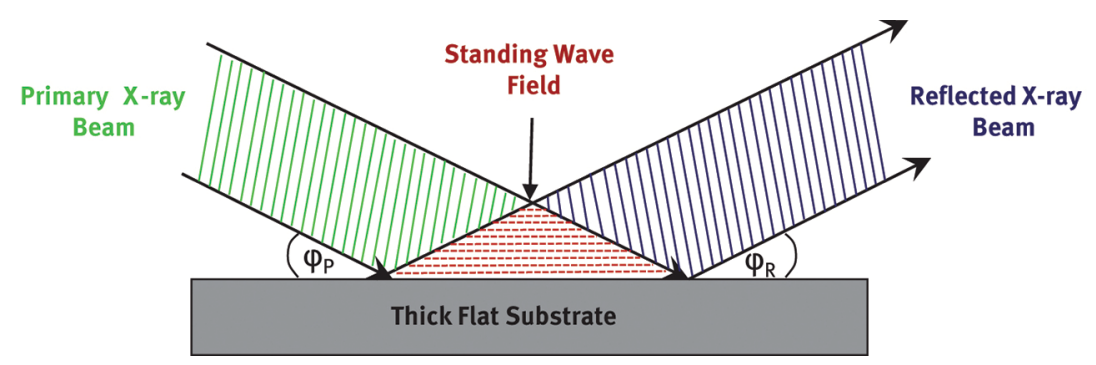

Figure 1: Primary and reflected X-ray beam create a standing wave field in front of a thick flat substrate.

When a thin homogenous layer is present on top of a thick substrate, an additional standing wave field can be observed within the thin-layer itself in addition to the one in front and can be used for layer identification.

In contrast to conventional XRF where the intensity $I_{\mathrm{O}}$ of the incoming beam decreases exponentially within a substrate, in TXRF atoms are excited directly proportional to the wavelength intensity. The fluorescence signal reflects the elemental composition of the sample and inhomogeneity of the primary wave field can be compensated by adding an internal standard. A sample deposited on a thick flat substrate is exposed to both the primary and reflected beam. As the reflectivity $R$ is nearly $100 \%$ below and at the critical angle, the fluorescence intensity $I$ is increased according to the following equation:

$$
I=I_{o}(1+R)
$$

where $I_{\mathrm{o}}$ is the intensity of the primary X-ray beam at glancing angles. For a granular residue on top of the substrate, the fluorescence intensity is almost constant below and at the critical angle as shown in Figure 2a. Since the primary beam does not penetrate beyond a few nanometers into the substrate, the background signal is very low. For example, for quartz, silicon or polycarbonate the background signal is about six orders of magnitude less than for conventional X-ray fluorescence. This decreased background and the enhanced fluorescence intensity are responsible for the high detection power and correspondingly low detection limits of TXRF.

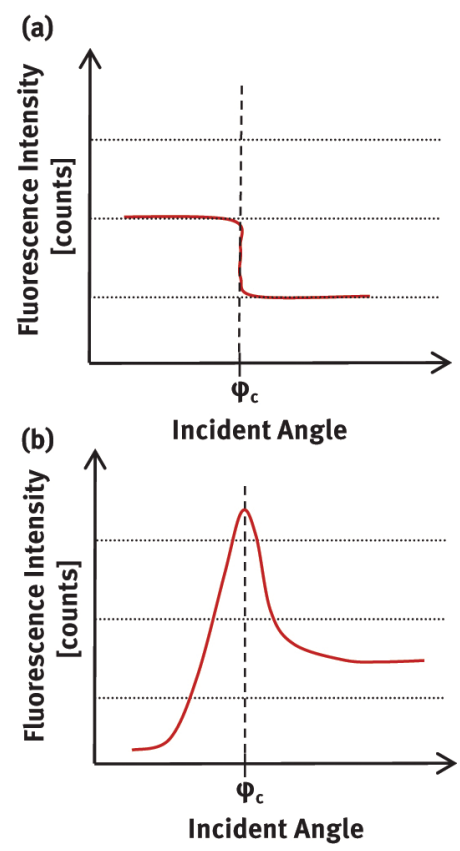

Figure 2: (a) Fluorescence intensity in dependency of incident angle $\varphi$ for a granular sample deposited on top of a thick flat substrate. Fluorescence intensity is constant below the critical angle $\varphi_{c}$ and decreases rapidly at the critical angle $\varphi_{c}$. (b) Fluorescence intensity in dependency of incident angle $\varphi$ for atoms embedded in a near surface layer. Fluorescence intensity increases when approaching the critical angle $\varphi_{c}$. It peaks at the critical angle and decreases rapidly for larger angles.

In Figure $2 b$, the fluorescence intensity at different glancing angles for atoms embedded in a near surface layer is displayed. The fluorescence intensity experiences a maximum at the critical angle in agreement with the X-ray standing wave theory. Surface layers can be characterized using different angles around the critical angle and useful information about their composition and thickness can be obtained. Important is that the layers are homogenous in composition. The instrumental set-up for these applications is somewhat different then for 
granular samples deposited on top of the substrate and requires a mechanism to change the incident angle in small increments. Surface and near surface layer characterization is important in the semiconductor industry where contaminations on wafers have to be determined to prevent failure of electronic devices.

\section{Instrumentation}

The general instrumental set-up for TXRF is simple. Only an X-ray source, a reflector or monochromator, a second reflector, serving as sample support or being the sample itself and a detector positioned on top of the second reflector are needed. A metal foil may be inserted at the exit of the tube to reduce the background signal and avoid blurring of angle dependent intensity profiles. The metal foil is not required for machines employing metal ceramic X-ray tubes and when performing trace analysis at fixed angle geometry. Figure 3 shows such basic instrumental set-up. The instrument is operated at atmospheric conditions thus no pumps, flanges or vacuum parts are needed.

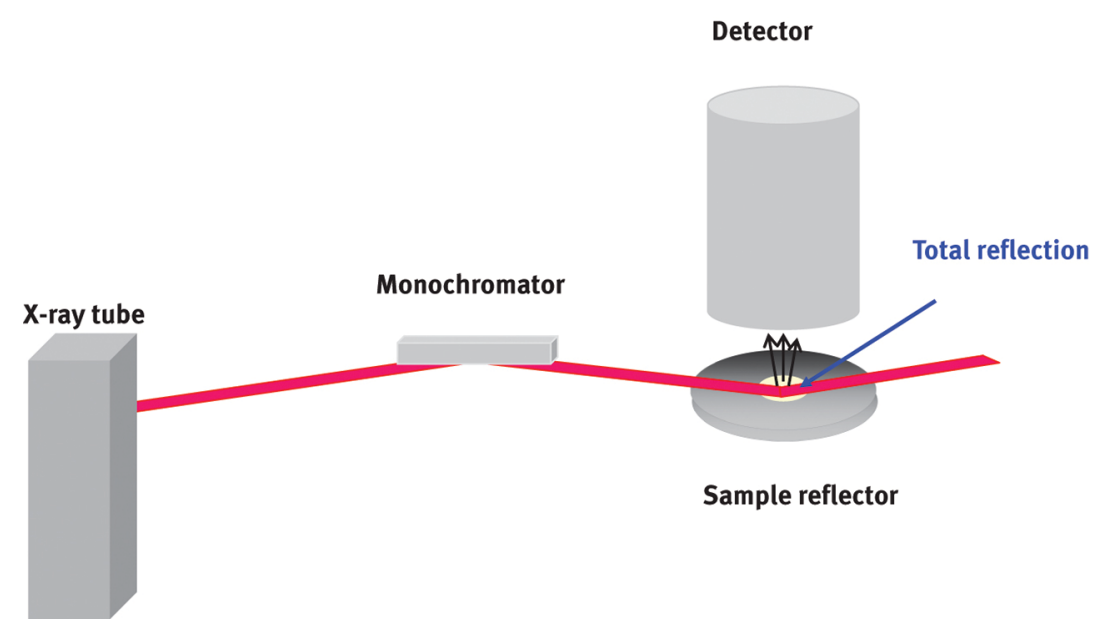

Figure 3: General set-up of TXRF consisting of X-ray source, monochromator, second reflector with sample and detector. A metal foil may be inserted in front of the tube to avoid blurring.

Successful excitation of a sample under total reflection requires a monochromatic well-collimated primary Xray beam with a divergence of less than $0.2 \mathrm{mrad}$. The beam is shaped like a thin paper sheet with a width of about $10 \mathrm{~mm}$ and a height of $10 \mu \mathrm{m}$. Thus, it will probe a small area of the substrate. The fluorescence radiation is captured by a detector, with a viewing area of about $30-50 \mathrm{~mm}^{2}$. To shape the beam precisely slits or diaphragms are placed in the optical path. For the analysis of granular deposits on a thick substrate, the incident angle should be set to less than the critical angle of total reflection, i.e. about $70 \%$ of that angle. In most cases, this corresponds to an incidence angle of about $0.06-0.07^{\circ}$ or $1.05-1.22 \mathrm{mrad}$ for the primary beam. The sample chamber might be flushed with nitrogen or helium to remove argon from the spectrum, which is part of the air present in the chamber. Removing argon permits for detection of elements such as silver and cadmium, which otherwise are obstructed by the argon peaks. When light elements with atomic numbers less than 12 are of interest the optical path, including sample support or second reflector, has to be evacuated to prevent absorption of fluorescence signals within the air space between sample and detector. This can be done by attaching the Xray source and the detector with a flange to a vacuum chamber in which the sample and optics are placed. Sometimes a similar approach is used when working with synchrotron radiation as excitation source [14-18].

When performing surface analysis, the instrument needs to be equipped with a mechanism allowing variation of the sample position in small increments around the critical angle of the primary X-ray beam.

\subsection{Excitation devices}

To excite atoms in a sample to fluorescence, a high-intensity X-ray beam is necessary. Water-cooled fine focus or air-cooled metal ceramic X-ray tubes satisfy this requirement and are generally used for trace and microanalysis. The most common anode materials are molybdenum, tungsten or chromium, with molybdenum having the widest energy range for elemental detection without change of tube conditions. The efficiency of excitation decreases for elements further away from the absorption edge of primary X-ray energy and chromium, tungsten or scandium anodes are recommended for detection of light elements instead of molybdenum. The 
use of a vacuum chamber in combination with the aforementioned anode materials improves the detection of light elements even further as it eliminates absorption of photons by air molecules. When performing surface analysis of wafers and thin-layer analysis rotating anodes are employed to satisfy the demand for lower detection limits and to compensate for losses of primary beam intensity by the monochromator. Rotating anodes show higher brilliance and better intensity resulting in an improvement of detection power [9].

The operating voltage of the tube should remain constant for all measurements as otherwise the instrument has to be re-calibrated for each voltage change. Tube current is not as important, but should be lowered when the dead time, the time it takes a detector to process the incoming photon pulses, is too high.

In recent years, synchrotron radiation has become more easily accessible. Its high brilliance and polarization allows for extremely low detection limits. The energy of the primary X-ray beam can be tuned with a multilayer crystal and the width of the beam manipulated with a slit allowing for step wise surface probing. The instrumental set-up is comparable to tube excitation and several beam lines at different synchrotron facilities are now available or adaptable for TXRF analysis [12].

\subsection{Monochromators}

The primary X-ray beam has to be monochromatic to be efficient in excitation of the sample. It is also necessary to eliminate the high-energy part of the beam which would otherwise be scattered within the sample, thus causing an increase in background signal. In trace and micro-analysis highly polished single crystal quartz prism or multilayers are employed for this purpose and are inserted into the optical path such that the primary X-ray beam strikes under grazing incidence and the device acts as total reflecting mirror. In addition, a thin metal foil may be inserted into the beam path to remove certain energies. For surface and thin-layer analysis, the primary X-ray beam has to be exactly monochromatic to obtain proper intensity profiles in dependency of the glancing angle. X-ray photons of different energies interfere with this process and obstruct the angle scan. To satisfy this requirement natural crystals or multilayers are used as monochromatizing units. The use of natural crystals shows better spectral selectivity but a reduction in intensity of the primary beam and rotating anode devices are typically employed to compensate for this as mentioned above. Multilayers have less spectral selectivity but yield a higher intensity of the primary beam. The selectivity can be improved by arranging two mulitlayers in parallel position to guide the beam in a zigzag pattern towards the sample.

\subsection{Sample positioning and detectors}

Positioning of the sample needs to be very precise as the incident angle is small with less than $0.1^{\circ}$. For trace and micro-analysis, a fixed sample position is realized with a precise positioning mechanism placing the sample exactly at the same spot for each analysis. In surface and thin-layer analysis, sample positioning is even more important as the sample has to be moved with respect to the beam for surface scanning and rotated around the critical angle for subsurface analysis. For this purpose, the sample is placed on a movable plane or stage, which can be rotated, tilted and adjusted in the horizontal $x$-, $y$-direction in small steps to allow for surface screening.

The sample support or the sample itself when performing surface analysis should be optically flat to allow for total reflection of the primary beam. The surface roughness has to be less than $5 \mathrm{~nm}$ and the waviness should not exceed $0.001^{\circ}$. The reflectivity of most commercially available sample supports exceeds $99 \%$. If using a sample support, it has to be contamination free and chemically inert when performing trace analysis. Materials satisfying these requirements and used most commonly are quartz, plexiglass ${ }^{\circledR}$ or polycarbonate, silicon and sapphire. Quartz, silicon, and sapphire are chemically very resistant and can be cleaned and reused for many analyses without losing their properties. Polycarbonate is cheap and easy to use, but does not withstand any acids or harsh chemicals. Glassy carbon and ultrathin supports such as silicon nitride $\left(\mathrm{Si}_{3} \mathrm{~N}_{4}\right)$ also satisfy the requirements, but are more exotic and therefore more expensive.

For detection of the spectra, a $\mathrm{Si}(\mathrm{Li})$ detector or a silicon drift detector (SDD) is used, which is placed directly on top of the sample at $90^{\circ}$ angle and at a distance of a few millimeter to obtain a large solid angle. This allows for maximum capture of fluorescence radiation by the detector and minimizes the absorption of soft X-rays in the space between detector and sample. For analysis of light elements, a high-purity germanium detector with or without beryllium window is more suitable as it has a better spectral resolution in the low energy range. If reflectivity is recorded in parallel to fluorescence radiation, a photodiode or CCD sensor can be employed behind the sample. 


\section{Analytical performance and sample preparation}

TXRF as a multi-element micro-analysis technique can be used to analyze trace or even ultra-trace quantities in many types of samples. For a successful analysis, the sample mass should not exceed a few $\mu \mathrm{g}$ and the sample should be thin (about 10-15 $\mu \mathrm{m}$ thick) in order to permit penetration of the primary beam through the sample for total reflection at the substrate surface. Matrix effects are low or even non-existent due to the low sample mass and thickness as absorption effects within the sample are practically eliminated. The lack of matrix effects permits for use of internal standardization as long as the standard is neither present in the sample nor will it interfere with the detection of the elements of interest. Samples suitable for analysis by TXRF are dried residues of solutions and suspensions, small grain size homogeneous powders, and thin sections. Typically some sample preparation is needed to obtain a homogeneous analyte and to limit its mass and size. Sometimes a sample can be analyzed directly. Examples are small amounts of homogenous powders of very fine grain sizes or thin sections of biological tissues.

Owing to its surface sensitivity, TXRF can be applied for surface and thin-layer analysis. This is of particular interest for determination of impurities or contaminations on semiconductor wafers or for thin film analysis. A variation of the glancing angle of the primary beam records fluorescence intensities at various angles and provides information about materials present on surfaces or within the top atomic layers of substrates. Detection limits are very low for TXRF and are comparable to most common analytical techniques used in atomic spectrometry and surface characterization.

To ensure ultra-trace quantification all sample preparation steps should be done under clean working conditions, ideally in a class 100 clean bench or laminar flow hood. Chemicals used should be of high-purity grade and the sample supports have to be free of surface contamination.

\subsection{Calibration and quantification}

Before quantitative analysis is possible, the system must be calibrated by measuring net intensities at different concentrations for each element. This involves preparation of multi-element standards containing two to six elements with concentrations of 1 to $10 \mu \mathrm{g} \mathrm{L}^{-1}$ in ultra-clean water. One element should be present in all standard solutions and serves as reference. A $50-100 \mu \mathrm{L}$ aliquot of the standard solutions is pipetted on a sample support or reflector in one or several steps to obtain a homogenous residue. The spectrum is then measured and added to the data base.

The relative sensitivity $S_{\mathrm{x}}$ for an element $x$ can then be calculated by the following equation:

$$
S_{x}=\frac{N_{x} / c_{x}}{N_{r e f} / c_{r e f}} * S_{r e f}
$$

where $N_{\mathrm{x}}$ and $N_{\text {ref }}$ are the net intensity for element $x$ and reference element ref and $c_{x}$ and $c_{\text {ref }}$ are the concentrations of these, respectively. $S_{\text {ref }}$ can be set to 1 as only relative sensitivities are calculated. Figure 4 shows relative sensitivities for selected elements in relationship to atomic number $Z$ using gallium as reference element for a particular instrumental set-up. Relative sensitivities are dependent on fluorescence production cross-section and detector efficiency. The relative sensitivities increase with atomic number $\mathrm{Z}$ and detector efficiency and are highest for heavy elements in the optimal detector range. 


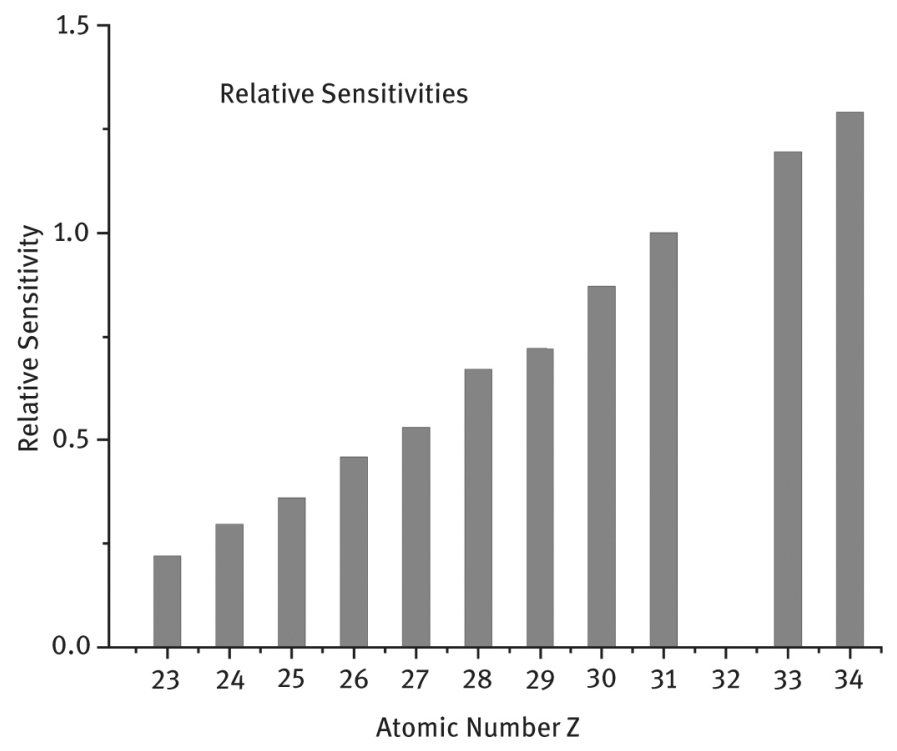

Figure 4: Relative sensitivities of selected elements in dependency of atomic number $\mathrm{Z}$ using gallium as reference element.

Calibration needs to be done only once per instrument as long as the components are not altered or exchanged in the equipment. Most instruments feature a software package which calculates net intensities using convolution techniques and only few element profiles need to be measured. The remaining ones can be extrapolated and fitted.

It is also possible to obtain relative sensitivities mathematically without intensity measurements. Several factors are incorporated in the equation including fluorescence yield and relative emission rate. When elemental standards are not available for certain elements, the relative sensitivity can be calculated by applying the abovementioned equations. Relative sensitivities are dependent on instrumental conditions and have to be updated when conditions such as the excitation source or monochromator change.

Quantification is done by addition of an internal standard of known concentration to the sample either before sample preparation or in case of powdered samples as a droplet on top of the powder. It was found that the elemental distribution is homogeneous when using an internal standard as long as the sample amount is less than $100 \mu \mathrm{g}$, little matrix is present and the sample is homogeneous [19]. To maintain linearity for quantification, the sample thickness should not exceed several tens of a micrometer and the sample amount should be within the following limits: for light, low-density matrices like organic materials less than $250 \mu \mathrm{g} / \mathrm{cm}^{2}$; for mediumdensity materials like mineral powders less than $140 \mu \mathrm{g} / \mathrm{cm}^{2}$, and for high-density materials like metal smudges less than $8 \mu \mathrm{g} / \mathrm{cm}^{2}$. The internal standard itself should be made up of an element not present in the sample and with a concentration in the medium concentration range of all elements to be determined. Most commonly used internal standard elements are gallium and yttrium. Both elements typically do not interfere with elements to be determined in a sample. In some cases when the sample is present in basic solution germanium can be used as internal standard. Elements with energies below $4 \mathrm{keV}(Z \leq 20)$ should be avoided as internal standard as particle size effects start to impact the accuracy of the measurements. For ultra-trace analysis of elements which have fluorescence energies close to those of the internal standard, the concentration of the internal standard should be as low as possible to avoid peak overlap, if a different element cannot be used as internal standard. Recording a spectrum without internal standard helps to estimate the concentration range of the internal standard needed and avoids too high or too low standard concentrations. When a digestion or separation step is required for a sample the internal standard should be added before those steps to monitor losses. For analysis of powdered samples, the internal standard has to be pipetted on top of the sample itself and dried for analysis, after the sample mass was determined by differential weighing using a micro-balance.

Elemental concentrations can be calculated as follows:

$$
c_{x}=\frac{N_{x} / S_{x}}{N_{i s} / S_{i s}} * c_{i s}
$$

where $c_{\mathrm{X}}$ and $c_{\text {is }}$ are the concentrations of the element to be determined and the internal standard (known), respectively; $N_{\mathrm{x}}$ and $\mathrm{N}_{\mathrm{is}}$ refer to the net intensities of element $x$ and internal standard; and $S_{\mathrm{x}}$ and $S_{\mathrm{is}}$ to the relative sensitivities. 
For example, the cobalt concentration of a sample was calculated to be $31.89 \mu \mathrm{g} \mathrm{L}^{-1}$ when using cupper as internal standard with a concentration of $50 \mu \mathrm{g} \mathrm{L}^{-1} . N_{\mathrm{Co}}$ and $N_{\mathrm{Cu}}$ were 9,902 counts and 24,962 counts and $S_{\mathrm{Co}}$ and $S_{\mathrm{Cu}} 0.53$ and 0.72 , respectively.

When the internal standard is deposited on top of a thin section, the concentration of the internal standard $c_{\text {is }}$ is determined by

$$
c_{i s}=\frac{\text { mass of internal standard on sample }}{\text { total mass of section }}
$$

Calibration and quantification for surface and thin-layer analysis has to be performed differently than for microand trace-analysis. It can be done by measuring external standards of pure elements, analyzing dried residues of a standard element or after spin coating of a solid support or wafer with a spiked solution. Internal standardization is not suitable for quantification as angle variation of the primary beam does influence the fluorescence intensity. An evaluation of the external standardization procedure using nickel as external standard showed that this approach is valid until about 150ng Ni [19]. Peak fitting and quantification has to be carried out by using the fundamental parameter method as known for conventional XRF [20].

\subsection{Detection limits}

According to the International Union of Pure and Applied Chemistry (IUPAC), the detection limit is the minimum concentration or mass of an analyte, which can be detected with a given confidence level [21]. Mathematically this is expressed as the minimum distinguishable signal $S_{\mathrm{m}}$ to be equal to the mean blank signal $\overline{S_{B L}}$ and its standard deviation $k_{\mathrm{SDBL}}$. A value of 3 is typically recommended for $k$ leading to:

$$
S_{m}=\overline{S_{B L}}+3_{S D B L}
$$

The detection limits for TXRF are several orders of magnitude lower than for conventional XRF and comparable to most atom spectrometric methods used for trace analysis or surface characterization such as atomic absorption spectrometry (AAS), inductively coupled plasma optical emission spectrometry (ICP-OES) and laser ablation inductively coupled mass spectrometry (LA-ICPMS). For transition metals and heavy elements, the detection limits are in the lower picogram range for most samples and can be somewhat improved by pretreatment and/or matrix removal. Detection limits are matrix dependent and were found to be for first row transition metals in the lower picogram range for biological matrices and slightly higher for powdered slurry samples. Very light elements like aluminum show higher detection limits as is typical for energy dispersive X-ray fluorescence methods. In the case of surface and subsurface analysis the detection limits are in the order of $10^{9}$ atoms $\left(\mathrm{cm}^{2}\right)^{-1}$ for transition metals and direct analysis. Those can be improved using special pretreatment techniques like vapor phase deposition (VPD) to about $10^{7}$ atoms $\left(\mathrm{cm}^{2}\right)^{-1}$. When synchrotron radiation is available as excitation source the detection limits are even better for direct determination and are reported to be $8^{*} 10^{7}$ atoms $\left(\mathrm{cm}^{2}\right)^{-1}$ for Ni directly on a wafer [22]. Table 2 shows the range of detection limits for commonly analyzed elements.

Table 2: Detection limits for commonly analyzed elements.

\begin{tabular}{lllll}
\hline$<\mathbf{2} \mathbf{p g}$ & $\mathbf{2 - 5} \mathbf{p g}$ & $\mathbf{5 - 1 0} \mathbf{~ g}$ & $\mathbf{1 0 - 1 0 0} \mathbf{~ g}$ & $\mathbf{1 0 0} \mathbf{~ p g}$ \\
\hline $\mathrm{Ni}, \mathrm{Cu}, \mathrm{Zn}, \mathrm{Ga}$, & $\mathrm{Mn}, \mathrm{Fe}, \mathrm{Co}, \mathrm{Br}$, & $\mathrm{Ti}, \mathrm{V}, \mathrm{Cr}, \mathrm{Sr}$, & $\mathrm{P}, \mathrm{S}, \mathrm{Ag}, \mathrm{Cd}$, & $\mathrm{Al}$ \\
$\mathrm{As}, \mathrm{Se}$ & $\mathrm{Rb}, \mathrm{Pb}, \mathrm{Bi}$ & $\mathrm{Y}, \mathrm{Zr}, \mathrm{Mo}, \mathrm{Rb}$ & $\mathrm{Sn}, \mathrm{Ba}, \mathrm{La}$ & \\
\hline
\end{tabular}

\section{Current generation machines}

Current instruments are divided between instruments used for chemical trace analysis and surface scanning of semiconductor wafers. Trace analysis instruments are substantially less expensive as only a fixed angle setup and a standard X-ray tube are needed instead of a stage and a rotating anode X-ray tube. Water cooling is not required for some machines, making those instruments versatile and portable. The main manufacturer of the trace element instruments are Bruker and Rigaku. Bruker has two models the S2PicoFox and the S4 
TStar with the latter one being able to accommodate sample supports of different shapes including microscopic slides. The Bruker instruments use metal ceramic X-ray tubes and SDDs and do not need water cooling. Thus they are portable and can be employed for field measurements. Rigaku offers its Nanohunter model for microanalysis purposes, but it employs a higher power X-ray tube which requires cooling. It is somewhat larger and heavier than the Bruker machines, but offers some features like programmable variable angle of incidence to probe thin layers. Both instruments are in a comparable price range of $\$ 120$ to $\$ 150 \mathrm{k}$ depending on the features. Smaller manufacturers of TXRF machines include G.N.R. Analytical Instruments Group, which offers a benchtop instrument (Horizon) and a floor standing unit (TX2000) featuring a Mo-tube and an SDD detector, and Ourstex Corporation, which offers a light weight $(8 \mathrm{~kg})$ benchtop instrument (OURSTEX200TX).

Rigaku also offers instruments for semiconductor manufacturing control. Those instruments require different capabilities and incorporate translation and goniometer stages as well as rotating anode X-ray tubes. The machines are also fully automated to be operated under ultra-cleanroom conditions with minimal maintenance and operation. Those instruments are substantially more expensive with at least $\$ 500 \mathrm{k}$ and more.

\section{How to perform the technique - practice}

\subsection{Micro- and trace-analysis}

Almost any sample can be analyzed by TXRF for its trace element content either directly or after some sample preparation steps. Such steps might include pre-concentration, digestion or matrix separation. Sometimes the samples do not need to be pre-treated but can be analyzed directly. Samples can be prepared as liquid solution, slurry, tissue section or as particulates. For liquids, typically an amount between 10 and $50 \mu \mathrm{L}$ is pipetted onto a clean sample support, dried to evaporate the liquid portion and then analyzed. In general, the internal standard should be added to the liquid solution at the beginning of the sample preparation process to ensure proper quantification. Recently, nano- and picoliter-dispensing systems have been introduced. These units are based on inkjet technologies and deliver single nano or picoliter droplets as well as droplet arrays. The small size of the droplets avoids absorption effects and permits for a homogeneous element distribution [23, 24]. Care has to be taken that the dried residue is homogeneous in appearance to avoid pockets of higher and lower concentration. In case of an uneven residue sample pretreatment such as dilution or digestion should be considered to improve the accuracy of data and detection limits.

Solids might be analyzed as a particle dab, tissue section or as a smear. Qualitative analysis can be performed by using mass percent of all analyzable elements. Quantification is somewhat more difficult for solid samples, but can be done by using the standard addition method or by weighing the sample and adding a certain amount of standard to calculate the amount of standard per sample mass. If particles are analyzed, it is helpful to add a little petroleum jelly or vacuum grease to help the particles adhere to the support surface. A reference or blank spectrum should be recorded to ensure the coating is clean enough for analysis.

Counting times range between 100 and $2000 \mathrm{~s}$ and depend on the concentrations to be determined. The general procedure for trace and ultra-trace analysis is summarized in Figure 5.

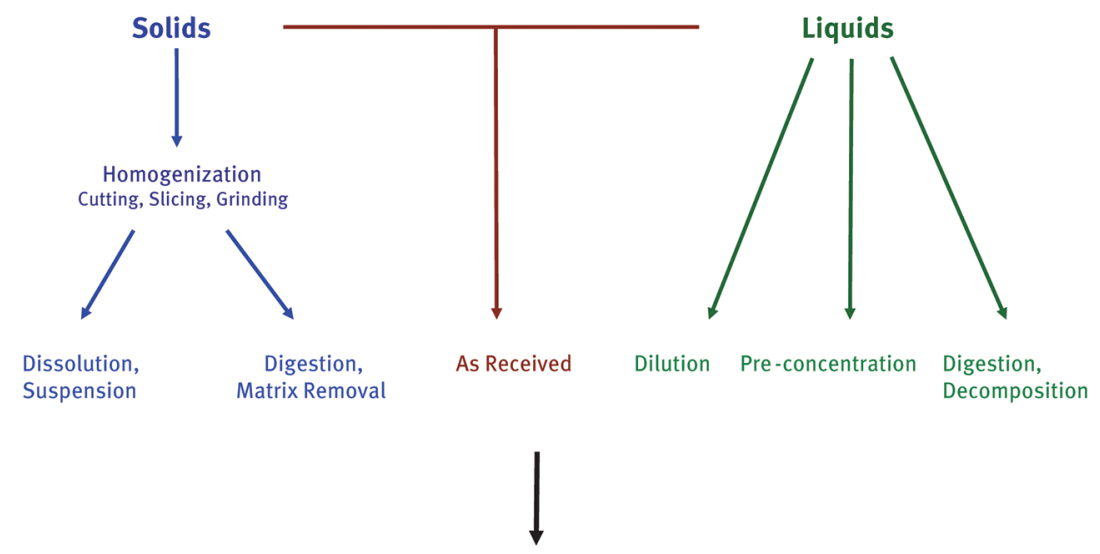

TXRF Analysis

Figure 5: Flowchart of general sample preparation steps involved in TXRF analysis. The left side of the figure summarizes the preparation of solid samples and the right side the preparation of liquid samples. The internal standard should be added at the same time or before any other liquid is added to the sample. 


\subsection{Environmental and geological applications}

Most types of water samples like drinking or tap water, mineral waters, and rain water are sufficiently low in matrix to allow for direct analysis $[25,26]$. For water samples containing more solid material such as waste water, river water or sea water, digestion with nitric acid or hydrochloric acid with and without hydrogen peroxide is recommended. Digestions can be open, or with microwave or high-pressure assistance. The latter ones require special equipment, but are also quantitative for volatile and semi volatile elements like mercury, selenium and arsenic. When silicates are present in a sample a small quantity of hydrofluoric acid can be added to ensure total dissolution. Extraction, adsorption, or preconcentration of the analyte of interest is another way to improve detectability. Several methods have been developed including the use of graphene oxide nanosheets for analysis of divalent metal ions and arsenic species, liquid-liquid microextraction for chromium speciation and selenium detection as well as preconcentration by means of co-deposition and microextraction to form complexes of rare earth elements [27-33]. Quantitative analysis of volatile elements like mercury has been achieved by complexation and oxidation [34].

Figure 6 shows the spectrum of a drinking water sample. The sample was only treated with $100 \mu \mathrm{g}$ $\mathrm{L}^{-1}$ gallium as internal standard for quantification. $10 \mu \mathrm{l}$ of the resulting solution was pipetted onto a clean quartz sample support, dried at $60^{\circ} \mathrm{C}$, and analyzed for $2000 \mathrm{~s}$. Detection limits were found to be below $10 \mathrm{pg}$ for most elements determined.

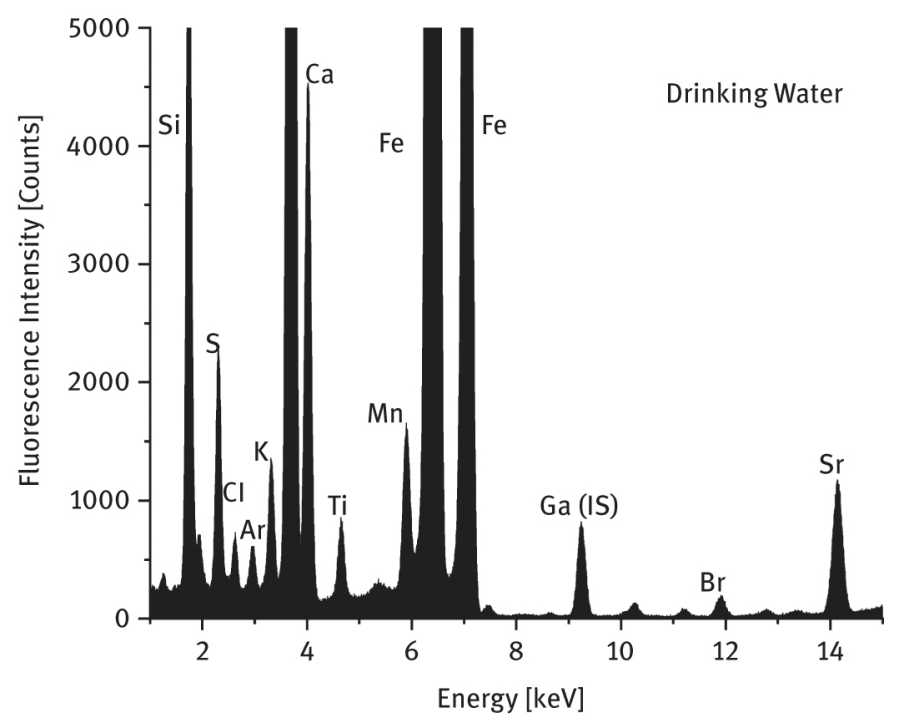

Figure 6: TXRF spectrum of a local drinking water sample with $100 \mu \mathrm{g} \mathrm{L}-1$ gallium as internal standard (IS).

Atmospheric aerosols or other fine particle samples can be dissolved in water or digested with acid. Filters used for aerosol collection can be either extracted or digested by acids and the resulting solution analyst. If using an impactor device the aerosol particles can be directly deposited on a sample support for trace analysis. In this case the support should be coated with petroleum jelly or vacuum grease to keep the particles sticking to the surface instead of bouncing off [35-37]. Figure 7 displays the spectrum of an atmospheric aerosol sample collected by filtration and after microwave digestion with concentrated nitric acid. $100 \mu \mathrm{g} \mathrm{L}^{-1}$ gallium was added as internal standard before the digestion step and $20 \mu \mathrm{l}$ of the digested solution was pipetted onto a clean quartz support. The solution was dried at $60^{\circ} \mathrm{C}$ and analyzed for $2000 \mathrm{~s}$. Detection limits were below 10pg for most elements. 


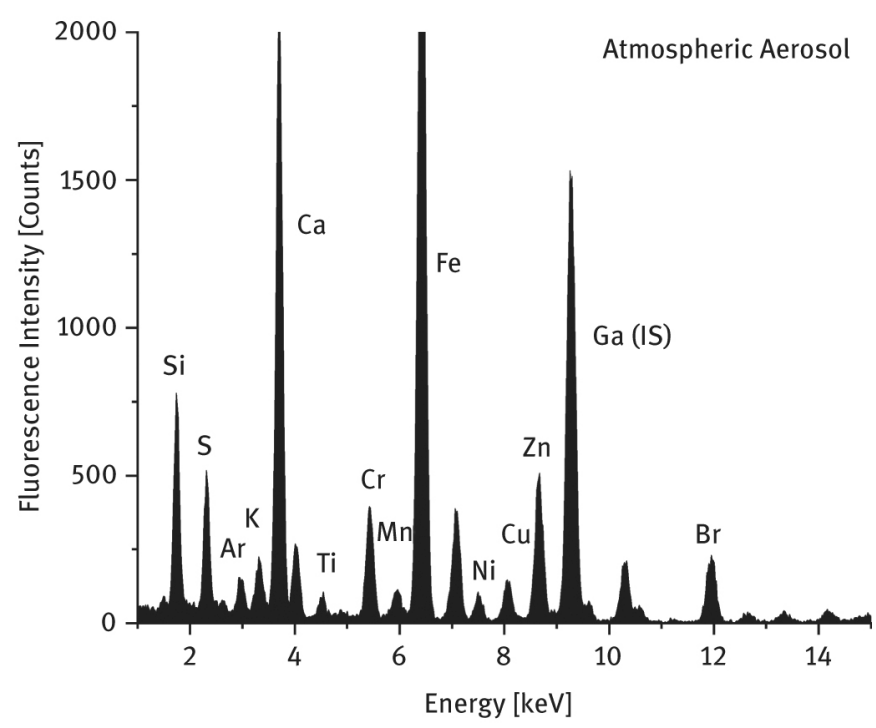

Figure 7: TXRF spectrum of an atmospheric aerosol sample after acid digestion and addition of gallium $\left(100 \mu \mathrm{g} \mathrm{L}^{-1}\right)$ as internal standard.

Most geological and soil samples require major sample preparation efforts due to their high organic or inorganic matrix content, if quantitative analysis is required. Most commonly acid digestion with or without hydrofluoric acid is performed or suspensions are made using water or non-aqueous solvents [38-41]. If quantification is not the goal, but simple fingerprint analysis is sufficient, the sample can be grinded using a mortar or mill to obtain a uniform particle size. Particles should be as small as possible to avoid absorption effects of the primary Xray beam when analyzed. For soil samples, extraction can be an option as can be complexation of the analytes of interest or a combination of both. Figure 8 shows the spectrum of New Ohio Red Clay a common material used to test the accuracy of analysis of geological samples. In this case a small amount of the clay material was directly dusted on the sample support and analyzed for fingerprint analysis. Detection limits were found to be in the lower nanogram to upper picogram range for the powdered clay sample.

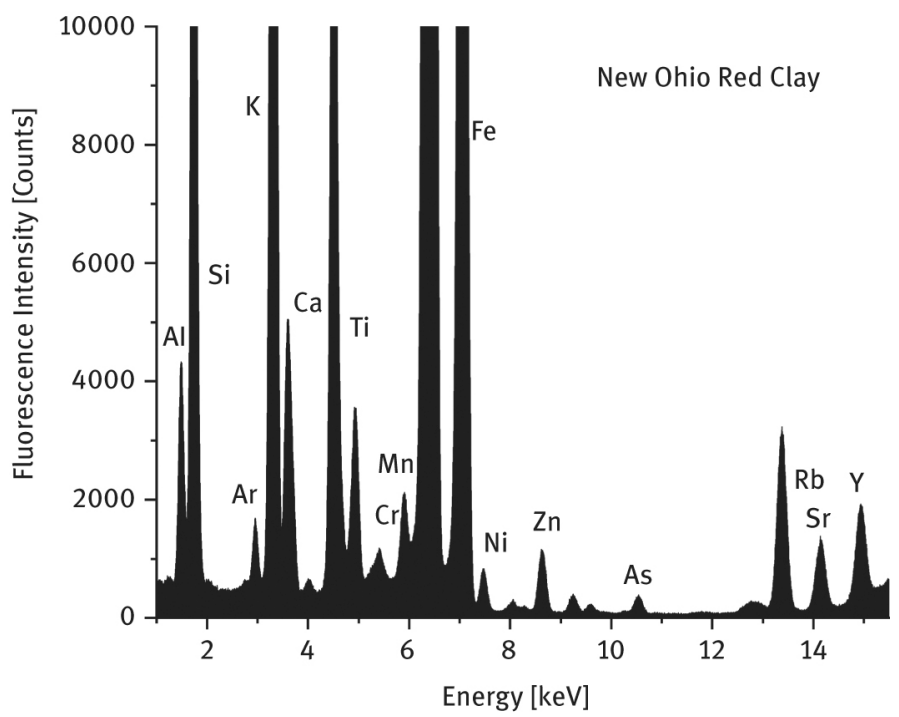

Figure 8: Fingerprint analysis of New Ohio Red Clay using TXRF. A small powdered amount was analyzed without addition of internal standard.

\subsection{Biological and food applications}

Biological and clinical materials generally need to be pretreated to remove the organic matrix which would increase the background signal and thus worsen the detection limits. Common pretreatment methods are ashing, acid digestion, or purification using chromatographic methods [42-50]. Mineral oil, vegetable oil or fatty acid containing samples like creams and lotions can be diluted with a solvent or if necessary subjected to cold oxygen plasma ashing to remove excess carbon. Tissue samples can be analyzed as thin sections embedded 
in paraffin or as thin cryogenic sections [51-53]. Quantification is possible by adding an internal standard on top of the section after the total weight of the sample has been determined. Analysis of body fluids like, urine, serum or plasma does not necessarily require a digestion step, but simple mixing with water and agitation often yields sufficiently reproducible results $[2,6,17,54,55]$.

Plant materials can be freeze dried and then grind to a fine powder using a mortar or mill. The fine powder can be either mixed with acids, water or an aqueous solution of Triton ${ }^{\circledR} \mathrm{X}-100$. The latter one is a detergent (polyethylene glycol tert-octylphenyl ether) used for breaking up cell membranes and provides for a more even particle distribution on the sample support. This leads to higher accuracy and reproducibility of the results [56-59].

Figure 9 shows the spectrum of a human lens collected during cataract surgery using the phacoemulsification procedure. The lens material was mixed with concentrated nitric acid (1:1 ratio) to digest most of the biological matrix and $100 \mu \mathrm{g} \mathrm{L}{ }^{-1}$ gallium was added as internal standard. $10 \mu \mathrm{l}$ of the resulting solution were pipetted onto a clean quartz sample support, dried at $60^{\circ} \mathrm{C}$ and analyzed for $2000 \mathrm{~s}$. Detection limits were between 5 and $20 \mathrm{pg}$ for this type of sample and sample preparation.

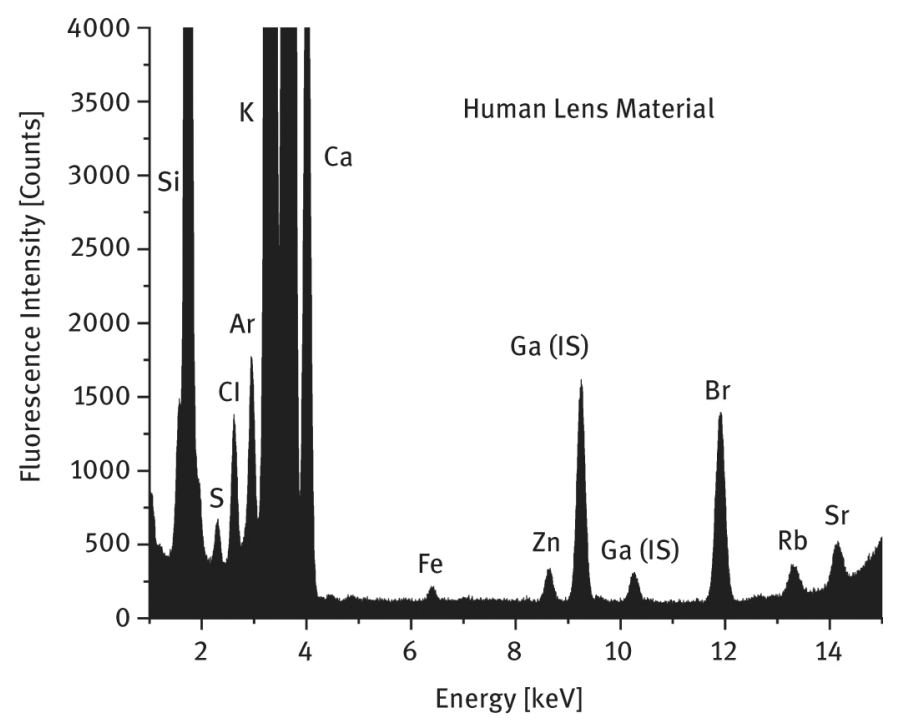

Figure 9: TXRF spectrum of a human lens sample collected during cataract surgery (1:1 sample: nitric acid). $100 \mu \mathrm{g}$ $\mathrm{L}^{-1}$ gallium was added as internal standard.

TXRF can be used to analyze selected elements in food, beverages, and dietary supplements [60-64]. For beverages, a small quantity of the sample is often only mixed with an internal standard and analyzed directly. [65-67]. If the beverage has a higher matrix content such as juices or wine and beer, the sample can be mixed with water, ethanol or nitric acid to obtain higher accuracy and reproducibility [68, 69]. Dietary supplements are treated like powdered or in case of herbal supplements plant leave samples. Grinding, homogenization and mixing with a solvent including the internal standard are common procedures yielding good results [59].

Figure 10 shows the TXRF spectrum of a black tea extract. A known quantity of black tea powder was extracted with hot water for 5 minutes and the extract analyzed. The internal standard $\left(100 \mu \mathrm{g} \mathrm{L}^{-1} \mathrm{Ga}\right)$ was added before extraction. $10 \mu \mathrm{l}$ of the extract was pipetted onto a clean quartz support, dried at $60^{\circ} \mathrm{C}$ and analyzed for $2000 \mathrm{~s}$. Detection limits were found to be between 1 and 10pg for most elements detected. 


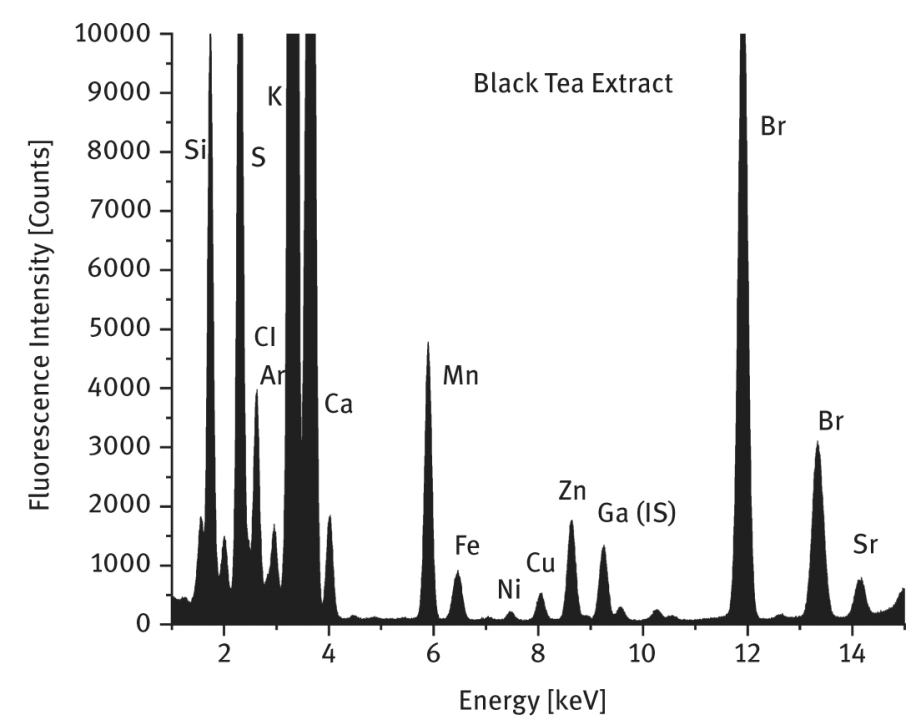

Figure 10: TXRF spectrum of a black tea extract sample. $100 \mu \mathrm{g} \mathrm{L}^{-1}$ gallium was added as internal standard.

\subsection{Cultural heritage applications}

One of the most notable features of TXRF is that it requires only minute amounts of sample material. Thus, the method lends itself for applications where sample material is sparse. One area where sample material is limited is in samples of cultural heritage $[4,70,71]$. Typically, a tiny amount of sample either taken with a cotton swap or from an area under restauration is sufficient to identify the pigment or ceramic used [5, 72]. This can be done during the restauration process and help select original pigments for restauration or even help authenticate a work of art [3,73]. Qualitative to semi-quantitative analysis of pigments from paintings or scripts as well as the base materials of ceramics or sculptures can be easily done with TXRF in this way [74-76]. If quantitative information is needed, for example in the case of ceramics or pottery, a small as possible sample amount should be selected, ground to a small homogeneous particle size and weight using an analytical balance. The powdered sample can then be digested with a variety of solvents depending on the elements of interest. Nitric acid, hydrochloric acid, or aqua regia mixed with small amounts of hydrofluoric acid are the most common solvents. Sometimes the sample is simply mixed with a diluted surfactant solution like Triton ${ }^{{ }_{-}}$ X100. The resulting slurry is pipetted on a sample support and analyzed. Important in this case is that the particle size is small and uniform as particle size effects can lead to absorption and errors.

Figure 11 shows the spectrum of a pottery shard used to make Mayan pottery during the Mesoamerican period. The original sample was grind to homogeneous particle sizes using a mortar and a known amount of the fine powder was diluted with ultrapure water. $100 \mu \mathrm{g} \mathrm{L}{ }^{-1}$ gallium was added as internal standard. The sample was shaken vigorously and $10 \mu \mathrm{l}$ of the slurry pipetted onto a clean quartz support. The sample was dried at $70^{\circ} \mathrm{C}$ and the dried residue analyzed for $2000 \mathrm{~s}$. Detection limits were between 1 and 10pg for most elements detected.

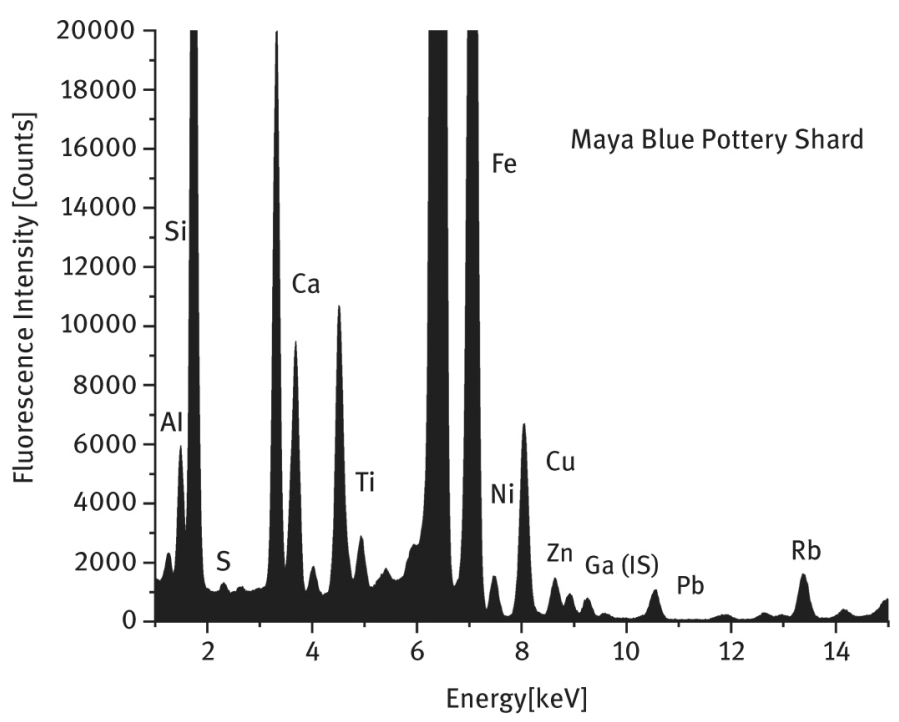


Figure 11: TXRF spectrum of a Mayan pottery shard after grinding, homogenization, mixing with water and addition of internal standard (100 $\mu \mathrm{g} \mathrm{L} \mathrm{L}^{-1}$ gallium).

\subsection{Other applications}

TXRF has been proven to be a useful method in a number of industrial applications. For instance the aging of an automotive catalyst can be characterized by analyzing the catalyst block after various stages of car use. The brick is pulverized, and digested with hot acids in a PTFE vessel for a defined amount of time. The digestion solution can be filtered, diluted and an internal standard added for quantification [77]. With the increasing demand of energy storage large rechargeable battery cells are an important commodity. TXRF analysis was used to determine the loss of specific capacity in rechargeable lithium ion batteries. For this NMCIII electrodes composed of $\mathrm{LiNi}_{1 / 3} \mathrm{Co}_{1 / 3} \mathrm{Mn}_{1 / 3} \mathrm{O}_{2}$ and with a certain mass loading were used. The batteries underwent several charge and discharge cycles and the amount of transition metals in the cell fluid was measured. The information obtained from this data was then used to calculate capacity loss [78-80]. Industrial samples containing high salt content as well as nuclear materials consisting of uranium and heavy water are accessible for TXRF analysis as well. In some cases sample can be analyzed directly, but mostly a sample pretreatment step involving acid digestion, extraction or separation is involved [18, 81-84]. In the pharmaceutical industry TXRF has been applied successfully to determine metal impurities in active pharmaceutical ingredients (APIs) using a variety of organic solvents including methanol and also nitric acid digestion as sample preparation steps. Results were compared to inductively couple plasma mass spectrometry (ICP-MS) and were found to be in good agreement for most samples and elements $[85,86]$.

\subsection{Surface and thin-layer analysis}

Surface analysis is possible when the samples are smooth and optically flat. Ideally suited for this are wafers as produced and used in the semiconductor industry. Therefore it is not surprising that most applications of surface and thin-layer analysis are found in this field [7, 8, 87]. TXRF instrumentation has been tailored since the 1990's for wafer control initially using only surface scanning, but more recently also for subsurface analysis. Different approaches are used to satisfy the need of the semiconductor industry for low detection limits and larger wafers. Direct analysis with and without chemical surface treatment as well as sputtering methods were developed [88-91]. Both uncoated and coated wafers can be characterized. For uncoated wafers surface analysis is performed whereas thin-layer analysis is applied for coated wafers. Typically fluorescence intensity profiles in dependency of the incident angle around the critical one are recorded. The profiles or angle scans provide information about the elemental composition and thickness of the surface and near surface layers. This approach is termed grazing incidence X-ray fluorescence or GI-XRF. When scanning at different areas of the wafer a surface map consisting of contaminants and types of contaminants can be obtained. In practice, some spots are selected and angle scans performed for those as the process is very time intensive and the wafer size is large $[8,12]$.

As mentioned angle scans are specific for each type of contamination and can be used to identify the most common types of contaminations when compared with calibration samples. Common surface contaminations are particles, thin layers or a thick bulk layer. Particle type contaminations show high intensities at small incident angles and the intensities decrease drastically at the critical angle. Thin layers show a distinct peak at the critical angle and thick bulk layers have low intensities at small angles and increasing intensities at higher incident angles. Figure 12 shows the fluorescence intensity profiles for these three types of contamination schematically. There are variation of those profiles depending on the mixture of contaminants, but an experienced user can easily recognize the type of contaminant even if present in combination with others by comparing with reference samples. 


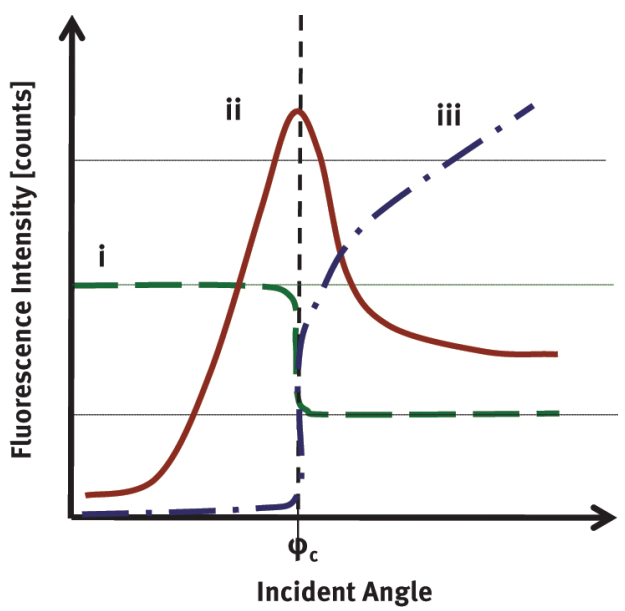

Figure 12: Fluorescence intensity profiles for three main types of contaminations present on semiconductors: (i) particle at the surface (ii) thin homogenous layer at or slightly below the surface, (iii) thick bulk layer.

It was found that angle dependent TXRF is quite suitable of analyzing implanted material within the first few nanometer of a substrate, but less able to provide detailed information beyond that depth. Nanoscale elemental distribution were measured by both laboratory and synchrotron TXRF and the laboratory based approach was able to determine the maximum implant concentration, but was less sensitive to recognize depth variations in concentration. By using a combination of angle resolved TXRF and X-ray reflectivity (XRR) it was possible to determine arsenic distributions in silicon wafers quite well. The data could be improved though when depth profile information obtained by secondary ion mass spectrometry (SIMS) was added. Thin layers of silver and copper were investigated before and after heat treatment by both laboratory and synchrotron TXRF and it was concluded that both methods could distinguish between heated and unheated layers, but only synchrotron TXRF could provide information on layer thickness [7, 9, 92-100].

Recently a new approach was suggested to provide a more detailed surface map of the wafer surface in a relative short time. For the so-called sweeping TXRF or S-TXRF for short, angle and height positioning of the system is only done at the first measurement position and not for every measurement position. A stable stage and rotating anode excitation ensures stability throughout the scanning and data acquisition process. With this set-up hafnium coverage was measured on a silicon wafer surface [101].

The detection limits for wafer analysis can be improved when the wafer is subjected to vapor phase decomposition (VPD) treatment. In this case the surface is slightly etched by hydrofluoric acid and silica $\left(\mathrm{SiO}_{2}\right)$ or silicon metal $(\mathrm{Si})$ are removed as silicone hexafluoride $\left(\mathrm{H}_{2} \mathrm{SiF}_{6}\right)$. The reaction also produces water droplets in which the surface contaminants are trapped. These droplets are dried and analyzed by TXRF. Special chambers for VPD are usually employed.

Both chemical etching and surface sputtering have been investigated to identify and quantify implanted material. Chemical etching follows a similar concept as VPD by removing surface material using hydrofluoric acid in combination with other chemicals. The etching solution as well as the resulting surface can be analyzed. In some cases the thickness of the removed layer is determined using interferometry or differential weighing [88-90, 102]. Sputtering is more elaborate as the sputtered material has to be deposited on a sample support in a proper fashion to be analyzed [91, 103]. A customized chamber is often necessary to achieve this. Both, the sputter deposited material and the resulting surface are typically analyzed to quantify the amount of subsurface material present. The data are then compared to either other surface sensitive methods such as X-ray photoelectron spectroscopy (XPS) or secondary ion mass spectrometry (SIMS) or to the original implant dose to determine accuracy [104].

Other less common applications of surface analysis include space returned samples and nanostructured materials [105-107]. Samples from the NASA Genesis mission were investigated for surface contamination after the space craft crash landed upon return to Earth. The sample collector materials were heavily contaminated at the surface and have to be carefully cleaned to obtain useful data for the mission. TXRF analysis can be used as a tool to monitor cleaning progress and Figure 13 shows two TXRF spectra acquired at different stages of the cleaning process. The black spectrum was recorded before and the red spectrum after the sample collector made of ultrapure sapphire $\left(\mathrm{Al}_{2} \mathrm{O}_{3}\right)$ was treated with concentrated nitric acid. The spectra show only surface contamination and not the acquired solar wind material, which is much deeper implanted (more than $50 \mu \mathrm{m})$ than surface analysis of the top few micrometer will be able to detect. 


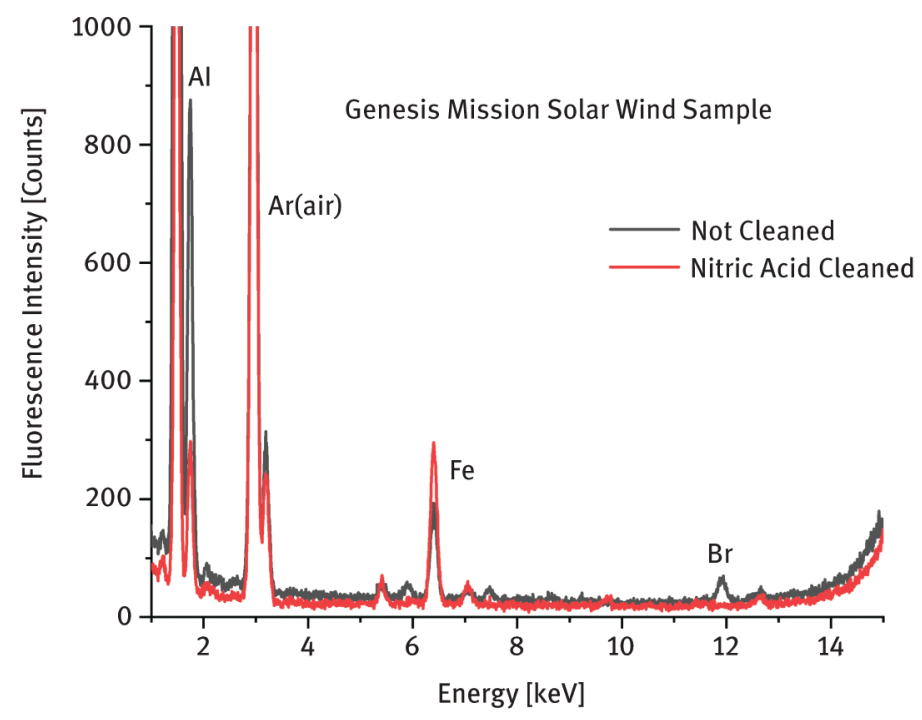

Figure 13: Genesis solar wind sample collector surface analysis before (black spectrum) and after cleaning with concentrated nitric acid (red spectrum).

The development and commission of new synchrotron beamlines dedicated to TXRF and GIXRF increased access to these facilities somewhat hence enabling applications where ultra-low detection limits, angle scanning capabilities, or tightly focused primary X-ray beams are required. The main applications are in the semiconductor and electronics development where thin-layer characterization is important, but it was also possible to determine abundances of selected solar wind elements in space returned samples using synchrotron radiation as excitation source [108-110]. Several beamlines, mostly located in Europe, are available for TXRF and GIXRF applications. Thin film and thin-layer analysis has been performed at BESSY II (Berlin, Germany), Elettra (Trieste, Italy), ESRF (Grenoble, France), and at SOLEIL (Saclay, France). Reference free GIXRF was successfully applied to characterize $\mathrm{Al}_{2} \mathrm{O}_{3}$ and $\mathrm{Sc}_{2} \mathrm{O}_{3}$ nanolayers on different substrates and to measure mass distributions of several elements for layered reference samples. The combination of GIXRF and XRR was used to identify inter diffusion of elements between layers consisting of $\operatorname{In}_{2} \mathrm{O}_{3}$ and $\mathrm{Ag}$ before and after annealing. A similar approach was adopted to characterize $\mathrm{Ta}_{2} \mathrm{O}_{5} / \mathrm{TiN}$ stacks with and without plasma treatment for the atomic layer deposition (ALD) process. GIXRF and XRR was also employed for the characterization of floating lipid monolayers as a function of molar fraction. Combining GIXRF with near edge $\mathrm{X}$-ray absorption fine structure (NEXAFS) measurements on a sample containing a $\mathrm{Ti} / \mathrm{Ti}_{2} \mathrm{O}_{3}$ layer provided besides depth information also information on the binding status of titanium. [111-120].

The surface morphologies of tungsten thin film structures and gold nanoparticles on silicon surfaces were investigated at the Indus-2 synchrotron facility (Indore, India) and the elemental distribution in mice brains with and without Alzheimer's disease after acid digestion were examined at the Brazilian National Light Laboratory (Campinas, Brazil) [121, 122].

\section{Data analysis}

Data analysis is straightforward as only relatively few peaks are present in an X-ray spectrum. Moreover, peaks are element specific, overlap is rare, and the peak ratios for $\mathrm{K}, \mathrm{L}$, and $\mathrm{M}$ lines are well known. Element identification is typically done by two strong peak fits like $K \alpha$ and $K \beta$ or $L \alpha$ and $L \beta$. Sometimes interferences are present between the $\mathrm{K} \alpha$ peak of one elements with the $\mathrm{K} \beta$ peak of another element, e.g. $\mathrm{Cr} \mathrm{K} \alpha$ and $\mathrm{V} \mathrm{K} \beta$. This can be remedied by using the $K \beta$ peak of chromium and $K \alpha$ peak of vanadium for peak identification. Sum peaks or pulse pile-up effects are a detector phenomenon and may occur at very high count rates when two different photons or pulses arrive at the detector at the same time. The detector cannot discriminate between the pulses or photons and those are shown as an additional peak representing the sum of the two photon energies $\mathrm{E}_{1}$ plus $\mathrm{E}_{2}$. It can be avoided by either dilution of the sample, or by matrix removal, and by reducing the primary beam intensity. Escape peaks are also a detector phenomenon and are produced for analytes with very high concentrations in the sample. The peaks arise from the detector material when photons with higher energies than the material produce photoelectrons within the detector. Most of the emitted photons are reabsorbed, but some can escape the detector. Escape peaks are mostly present for high-purity germanium detectors (HP Ge Detector). The escape peaks will be found in the spectrum at energies less than the analyte peak. For Germanium 
detectors escape peaks are $9.9 \mathrm{keV}$ less than the analyte peak and for Si detectors an escape peak is $1.74 \mathrm{keV}$ less than the analyte peak.

The basic process of element identification can be broken down into three parts:

peak localization, peak identification and element identification. Net Intensities of peaks are used for element quantification. Net intensities correspond to pure element peaks, which are free of background and peak overlap. To obtain net intensities for each element a spectrum has to be processed and several mathematical methods are available for this. The most common and accurate approach involves the comparison of background free single-element spectra with the sample spectrum. For this, spectra of pure elements are recorded and saved in a spectra library. Those element spectra are then fitted with the sample spectrum, a final least squares fit is done and the resulting net intensities are read. Commercial instruments have their own proprietary software for peak processing and calculation of net intensities. There are also a number of software packages available, which can be used for this. Examples are Origin (Originlab.com), IgorPro (wavemetrics.com), Peakfit (Sigmaplot.co.uk), Python (plot.py), Mathlab (mathworks.com), and ROOT (root.cern.ch).

If a peak cannot be clearly identified, it might be an artifact such as a sum peak or escape peak. Sometimes the sample is not smooth enough or consists of too much organic matrix. This leads to an increase in background scattering, which can be mistakenly identified as a peak.

In such cases sample preparation has to be adjusted to remove or reduce the matrix. Quantitative analysis is done using internal standards as described already.

\section{Summary}

TXRF is a multi-element micro-analytical method capable of analyzing trace and ultra-trace quantities in a multitude of samples. It utilizes the total reflection of the primary X-ray beam at or below the critical angle of incidence. At this angle, the fluorescence intensity is substantially enhanced for samples present as a thin granular residue or as a homogenous layer deposited at the surface of a thick substrate leading to detection limits in the lower ng to upper pg range for most elements. Generally, two types of application do exist: microand trace-analysis as well as surface and thin-layer analysis.

For micro- and trace-analysis a small amount of the solid or liquid sample is deposited on an optically flat substrate, typically quartz or polycarbonate. The dried residue is analyzed at a fixed angle setting slightly below the critical angle. Quantification is carried out by means of internal standardization.

For surface and thin-layer analysis the surface of an optically flat substrate is scanned. Variations of the incident angle of the primary X-ray beam provide information about the type and sometimes also the amount of material present at or slightly below the surface of the substrate.

Table 3 summarizes the most common applications of TXRF.

Table 3: Summary of most common applications of TXRF.

\begin{tabular}{llll}
\hline Biomedical & Environmental & Industrial & Other \\
\hline Body fluids & Plant materials & High-purity chemicals & Forensics \\
Tissue & Water & Metals and ores & Art and cultural heritage \\
Hair & Particulate matter & Oils, creams, and greases & Food and pharmaceuticals \\
& Soil and rock & Films, foils, implants, & \\
& & semiconductors & \\
\hline
\end{tabular}

\section{Conclusions}

TXRF spectrometry is a versatile multi-element and surface sensitive analysis method capable of detecting elements at the trace and ultra-trace level. It is non-destructive and only minute amounts of sample material in the order of a few micrograms or microliters are required for quantitative analysis. Matrix effects are little or non-existent at this small sample amounts reducing sample preparation time and permitting for direct analysis of many types of materials. Solids and dried liquid residues can be analyzed qualitatively and quantitatively by using internal standardization. The main fields of application for TXRF in micro- and trace-analysis are environmental, biological, art historical and industrial samples. Due to its surface sensitivity and non-destructive nature TXRF has been employed in semiconductor production control, thin film analysis, and the study of ma- 
terials embedded within the uppermost layers of a solid substrate. TXRF has gained in popularity over the last decades due to its ease of use, low costs, and field research capability.

\section{References}

[1] Yoneda Y, Horiuchi T. Optical flats for use of X-ray spectrochemical micro analysis. Rev Sci Instrum. 1971;42:1069-70.

[2] Telgmann L, Holtkamp M, Künnemeyer ], Celhard C, Hartmann M, Klose A, et al. Simple and rapid quantification of Cd in urine and blood plasma samples by means of total reflection X-ray fluorescence (TXRF). Metallomics. 2011;3:1035-2213.

[3] Vazquez C, Custo G, Barrio N, Burucua ], Boeykens MF. Inorganic pigment study of the San Pedro Conzalez Telmo Sibyls using total reflection X-ray fluorescence. Spectrochim Acta. 2010;B65:852-8.

[4] Detcheva AK, Velinova RH, Manoylova AK, Ivanova EH. Study on the colouration of Bulgarian late-antique and medieval archaeological glass finds by a validated total reflection X-ray fluorescence procedure. Phys Chem Classes: Eur ] Class SciTechnol. 2017;B58:217-25.

[5] Von Bohlen A. Quantitative analysis of minor and trace elements in historical varnishes using total reflection X-ray fluorescence. Anal Lett. 2004;37:491-8.

[6] Hernandez-Caraballo EA, Marco-Parra LM. Direct analysis of blood serum by total reflection X-ray spectrometry and application of an artificial neural network approach for cancer diagnosis. Spectrochim Acta. 2003;B58:2205-13.

[7] Sparks CM, Lanee S, Beebe M, Page M. Photovoltaic substrates and hafnium based gate dielectrics characterized with total reflection Xray fluorescence. Spectrochim Acta. 2008;B63:1351-4.

[8] Hellin D, de Gendt S, Valckx N, Mertens PW, Vinckier C. Trends in total reflection X-ray fluorescence spectrometry for metallic contamination control in semiconductor nanotechnology. Spectrochim Acta. 2006;B61:496-514.

[9] Pahlke S, Fabry L, Kotz L, Mantler C, Ehmann T. Determination of ultratrace contaminants on silicon wafer surfaces using total reflection X-ray fluorescence TXRF'state-of-the-art'. Spectrochim Acta. 2001;B56:2261-74.

[10] lida A, Yoshinaga A, Sakurai K, Gohshi Y. Synchrotron radiation excited X-ray fluorescence analysis using total reflection of X-rays. Anal Chem. 1986;58:394-7.

[11] Jenkins R. X-ray fluorescence spectrometry. 2nd ed. New York: Wiley and Sons; 1999.

[12] Klockenkämper R, von Bohlen A. Total reflection X-ray fluorescence analysis and related methods. 2nd ed. Hoboken: Wiley and Sons; 2015.

[13] Beckhoff B, Kanngiesser B, Langhoff N, Wedell R, Wolff H, editors. Handbook of practical X-ray fluorescence analysis. Berlin, Heidelberg: Springer; 2006

[14] Dhara S, Misra NL, Aggarwal SK, Ingerle D, Wobrauschek P, Streli C. Determination of low atomic number elements in real uranium oxide samples using vacuum chamber total reflection X-ray fluorescence. X-ray Spectrom. 2014;43:108-11.

[15] Maderitsch A, Smolek S, Wobrauschek P, Streli C, Takman P. Feasibility study of total reflection X-ray fluorescence analysis using a liquid metal jet X-ray tube. Spectrochim Acta. 2014;B99:67-9.

[16] Maderitsch A, Ingerle D, Bretschneider T, Rauwolf M, Pflumm C, Buchholz H, et al. Analysis of organic multilayer structures using a combined grazing incidence X-ray fluorescence/X-ray reflectivity approach. Spectrochim Acta. 2018;B148:188-92.

[17] Rauwolf M, Vanhoof C, Tirez K, Maes E, Ingerle D, Wobrauschek P, et al. Total reflection X-ray fluorescence measurements of $S$ and $P$ in proteins using vacuum chamber specially designed for low Z elements. Spectrochim Acta. 2014;B101:118-22.

[18] Sanyal K, Dhara S, Misra NL. Improved approach for the determination of low Z elements in uranium samples using a vacuum chamber TXRF. X-ray Spectrom. 2017;46:442-7.

[19] Horntrich C, Smolek S, Maderitsch A, Simon R, Kregsamer P, Streli C. Investigation of elemental distribution and homogeneity of TXRF samples using SR-micro-XRF to validate the use of an internal standard and improve external standard quantification. Anal Bioanal Chem. 2011;400:2649-54.

[20] Beckhoff B, Fliegauf R, Kolbe M, Müller M, Weser], Ulm G. Reference-free total reflection X-ray fluorescence analysis of semiconductor surfaces with synchrotron radiation. Anal Chem. 2007;79:7373-82.

[21] International Union of Pure and Applied Chemistry (IUPAC). Compendium of chemical technology, 2nd ed. McNaught A.D; Wilkinson, A. Ed., 1997 (ISBN 0-86542-684-8).

[22] Pianetta P, Baur K, Brennan S, Werho D, Wang J. Application of synchrotron radiation to TXRF of metal contamination on silicon wafer surfaces. Superficies Vacio. 1999;9:17-21.

[23] Wastl A, Stadlbauer F, Prost ], Horntrich C, Kregsamer P, Wobrauschek P, et al. Nanoliter deposition unit for pipetting droplets of small volumes for total reflection X-ray fluorescence applications. Spectrochim Acta. 2013;B82:71-5.

[24] Sparks CM, Fittschen UA, Havrilla C]. Picoliter solution deposition for total reflection X-ray fluorescence analysis of semiconductor samples. Spectrochim Acta. 2010;B65:805-11.

[25] Rodriguez Castro MC, Vilches C, Torremorrell A, Vazquez C, Giorgi A. Total reflection X-ray fluorescence in environmental and geochemical studies: unveiling solute provenance in streams during rain episodes. X-ray Spectrom. 2016;45:225-32.

[26] Borgese L, Dalipi R, Riboldi A, Bilo F, Zacco A, Federici S, et al. Comprehensive approach to the validation of the standard method for total reflection X-ray fluorescence analysis of water. Talanta. 2018;181:165-71.

[27] Sitko R, Janik P, Zawisza B, Talik E, Margui E, Queralt I. Green approach for ultratrace determination of divalent metal ions and arsenic species using total reflection $X$-ray fluorescence spectrometry and mercapto-modified graphene oxide nanosheets as a novel adsorbent. Anal Chem. . 2015;87:3535-42.

[28] Bahadir Z, Bulut VN, Hidalgo M, Soylak M, Margui E. Cr speciation in water samples by dispersive liquid-liquid micro extraction combined with total reflection X-ray fluorescence spectrometry. Spectrochim Acta. 2016;B115:46-51. 
[29] Oskolok KV, Monogarova OV, Alov NV. Total reflection X-ray fluorescence determination of rare earth elements in mineral waters using combined preconcentration techniques. Anal Lett. 2017;50:2900-7.

[30] Romero V, Costas-Mora I, Lavilla I, Bendicho C. Headspace thin-film microextraction onto graphene membranes for specific detection of methyl(cyclopentadienyl)-tricarbonyl manganese in water samples by total reflection X-ray fluorescence. Spectrochim Acta. 2016;B126:65-70.

[31] Mihucz VG, Enesei D, Veszely A, Bencs L, Pap-Balasz T, Ovari M, et al. A simple method for monitoring of removal of arsenic species from drinking water applying on-site separation with solid phase extraction and detection by atomic absorption and X-ray fluorescence based techniques. Microchem ]. 2017;135:105-13.

[32] Margui E, Hidalgo M. Analytical capabilities of two-phase hollow-fiber liquid phase microextraction for trace multi element determination in aqueous samples by means of portable total reflection X-ray instrumentations. Turk ] Chem. 2016;40:1002-11.

[33] Floor G, Margui E, Hidalgo M, Queralt I, Kregsamer P, Streli C, et al. Study of selenium sorption processes in volcanic ash using total reflection X-ray fluorescence (TXRF). Chem Ceol. 2013;352:19-26.

[34] Holtkamp M, Elseberg T, Wehe CA, Sperling M, Karst U. Complexation and oxidation strategies for improved TXRF determination of mercury in vaccines. J Atomic Anal Spectrom. 2013;28:719-23.

[35] Schmeling M. Characterization of urban air pollution by total reflection X-ray fluorescence. Spectrochim Acta. 2004;B59:1165-71.

[36] Klockenkämper R, Bayer H, von Bohlen A. Total reflection X-ray fluorescence analysis of airborne particulate matter. Adv X-Ray Anal ]pn. 1995;26s:41-6.

[37] Prost], Wobrauschek P, Streli C. Quantitative total reflection X-ray fluorescence analysis of directly collected aerosol samples. X-ray Spectrom. 2017;46:454-60.

[38] Towett EK, Sheperd KD, Cadisch G. Quantification of total environmental concentrations in soils using total reflection X-ray fluorescence spectroscopu (TXRF). Sci Total Environ. 2013;463/464:374-88.

[39] Torrent L, Iglesias M, Hidalgo M, Margui E. Analytical capabilities of total reflection X-ray fluorescence spectrometry for silver nanoparticles determination in soil adsorption studies. Spectrochim Acta. 2016;B126:71-8.

[40] Alov N, Sharanov P. Elemental analysis fo copper-zinc ores by total reflection X-ray fluorescence using non-aqueous suspensions. Anal Lett. 2018;51:1789-95.

[41] Bilo F, Borgese L, Cazzago D, Zacco A, Bontempi E, Guarneri R, et al. TXRF analysis of soils and sediments to $\underline{\text { assess environmental con- }}$ tamination. Environ Sci Pollut Res. 2014;21:13208-14.

[42] Margui E, Ricketts P, Fletcher H, Karydas AC, Migliori A, Leani J], et al. Total reflection X-ray fluorescence as a fast multi element technique for human placenta sample analysis. Spectrochim Acta. 2017;B130:53-9.

[43] Fiedor ], Ostachowicz B, Baster M, Lankosz M, Burda K. Quantification of purple non-sulfur phototrophic bacteria and their photosynthetic structures by means of total reflection X-ray fluorescence spectrometry. ] Atomic Anal Spectrom. 2016;31:2078-88.

[44] Wrobel PM, Bala S, Czyzychi M, Colasik M, Librowski T, Ostachowicz B, et al. Combined micro-XRF and TXRF methodology for quantitative elemental imaging of tissue samples. Talanta. 2017;162:654-9.

[45] Bilo F, Moscoso S, Borgese L, Delbarba MV, Zacco A, Bosio A, et al. Total reflection X-ray fluorescence spectroscopy to study lead and zinc accumulation in zebrafish embryos. X-ray Spectrom. 2015;44:124-8.

[46] Allegretta I, Porfido C, Panzarino O, Fontanella MC, Beone CM, Spagnuolo M, et al. Determination of As concentration in Earthworm coelomic fluid extracts by total reflection X-ray fluorescence spectrometry. Spectrochim Acta. 2017;B130:21-5.

[47] Heroes E, Rip ], Beullens M, Van Meerveld L, deGendt S, Bollen M. Metals in active site of native protein phosphatase-1.] Inorganic Biochem. 2015;149:1-5.

[48] Kubala-Kukus A, Arabeski M, Stabrowa I, Bana D, Rozanski W, Lipinski M, et al. Application of TXRF and XRPD techniques for analysis of elemental and chemical composition of human kidney stones. X-ray Spectrom. 2017;46:412-20.

[49] Fernandez-Ruiz R, Redrejo M], Friedrich E], Ramos M, Fernandez T. Evaluation of bioaccumulation kinetics of gold nanorods in vital mammalian organs by means of total reflection X-ray fluorescence spectrometry. Anal Chem. 2014;86:7383-90.

[50] Lankosz MW, Grzelak M, Ostachowicz B, Wandzilak A, Szczerbowska-Boruchoswka M, Wrobel P, et al. Application of the total reflection $X$-ray fluorescence method to the elemental analysis of brain tumors of different types and grades of malignancy. Spectrochim Acta. 2014;B101:98-105.

[51] Magalhaes T, von Bohlen A, Carvalho ML, Becker M. Trace elements in human cancerous and health tissues from the same individual: A comparative study by TXRF and EDXRF. Spectrochim Acta. 2006;B61:1185-93.

[52] Fernandez-Ruiz R. TXRF spectrometry as a powerful tool for the study of metallic traces in biological systems. Dev Anal Chem. 2014a;1:114.

[53] Von Bohlen A, Klockenkämper R, Tölg G, Wiecken B. Microtome sections of biomaterials for trace analysis by TXRF. Fresenius Zeitschrift für Analytische Chemie. 1988;331:454-8.

[54] Majewska U, Lyzwa P, Lyzwa K, Banes D, Kubala-Kukus A, Wudarczyk-Mocho ], et al. Determination of element levels in human serum: total reflection X-ray fluorescence applications. Spectrochim Acta. 2016;B122:56-61.

[55] Jablan ], Inic S, Stosnach H, Hadziabdic MO, Vujic L, Domijan A-M. Level of minerals and trace elements in the urine of the participants of mountain ultra-marathon race. J Trace Elem Med Biol. 2017;41:54-9.

[56] Bilo F, Borgese L, Dalipi R, Zacco A, Ferici S, Masperi M, et al. Elemental analysis of tree leaves by total reflection X-ray fluorescence: new approaches for air quality monitoring. Chemosphere. 2017;178:504-12.

[57] Woelfl S, Ovari M, Nimtsch ], Neu TR, Mages M. Determination of trace elements in fresh water rotifers and ciliates by total reflection X-ray fluorescence spectrometry. Spectrochim Acta. 2016;B116:28-33.

[58] Hoehner R, Tabatabaei S, Kunz-H-H, Fittschen U. A rapid total reflection X-ray fluorescence protocol for microanalysis of ion profiles in Arabidopsis thaliana. Spectrochim Acta. 2016;B125:159-67.

[59] Stosnach H. Analytical determination of selenium in medical samples, staple food, and dietary supplements by means of total reflection X-ray fluorescence spectroscopy. Spectrochim Acta. 2010;B65:859-63. 
[60] Bilo F, Lodolo M, Borgese L, Bosio A, Benassi L, Depero LE, et al. Evaluation of heavy metal contamination from environmental to food matrix by TXRF: the case of rice and rice husk. J Chem. 2015a. doi:10.1155/2015/274340.

[61] Borgese L, Bilo F, Dalipi R, Bontempi E, Depero LE. Total reflection X-ray fluorescence as a tool for food screening. Spectrochim Acta. 2015;B 113:1-15.

[62] Dalipi R, Margui E, Borgese L, Depero L. Multielement analysis of vegetal food stuff by means of low power total reflection X-ray fluorescence spectrometry. Food Chem. 2017;218:348-55.

[63] Margui E, Marquez AF, Prisal ML, Hidalgo M, Queralt I, Carvalho ML. Total reflection X-ray spectrometry for trace elements assessment in edible clams. Appl Spectrosc. 2014;68:1241-6.

[64] Monticelli D, Cinosi A, Siviero C, Seralessandirni L. Trace element determination in soy sauce: A novel total reflection X-ray fluorescence procedure and comparison with inductively coupled plasma mass-spectrometry. Spectrochim Acta. 2018;B146:16-20.

[65] Dalipi R, Margui E, Borgese L, Bilo F, Depero LE. Analytical performance of benchtop total reflection X-ray fluorescence instrumentation for multi element analysis of wine samples. Spectrochim Acta. 2016;B120:37-43.

[66] Dalipi R, Borgese L, Tsuji K, Bontempi E, Depero LE. Elemental analysis of teas, herbs and their infusions by means of total reflection X-ray fluorescence. J Food Compos Anal. 2018;67:128-34.

[67] Shand CA, Wendler R, Dawson L, Yates K, Stephenson H. Multivariate analysis of Scotch whisky by total reflection X-ray fluorescence and chemometric methods: a potential tool in the identification of counterfeits. Anal Chim Acta. 2017;976:14-24.

[68] Gama EM, Nascentes CC, Matos RP, Rodrigues CC. A simple method for the multi-elemental analysis of beer using total reflection X-ray fluorescence. Talanta. 2017;174:274-8.

[69] Schmeling M. Analysis of beverages by total reflection X-ray fluorescence. Spectroscopy. 2017;23:28-9.

[70] Crina Anca Sandu I, Helena de Sa M, Pereira Costa M. Ancient gilded art objects from European cultural heritage: a review on different scales of characterization. Surf Interface Sci. 2011. doi:10.1002/sia3740.

[71] Lyubomirova V, Djingova R, Kuleff I. Comparison of analytical techniques for analysis of archeological bronze. Archeometry. 2015;57:67786.

[72] Vazquez C, Maier MS, Parera SD, Yacobaccio H, Sola P. Combining TXRF, FT-IR, and GC-MS information for identification of inorganic and organic components in black pigments of rock art from Alero Hornillos 2 (JuJuy, Argentina). Anal Bioanal Chem. 2008;391:1381-7.

[73] Ardid M, Ferrero ]L, Juanes D, Lluch ]L, Roldan C. Comparison of total reflection X-ray fluorescence spectrometers for art and archeometric studies. Spectrochim Acta. 2004;B59:1581-6.

[74] Cariati F, Fermo P, Gilardoni S, Galli A, Milazzo M. A new approach for archeological ceramics analysis using total reflection X-ray fluorescence spectrometry. Spectrochim Acta. 2003;B58:177-85.

[75] Bonizzoni L, Galli A, Gondola M, Martini M. Comparison between XRF, TXRF and PXRF analyses for provenance classification of archeological bricks. X-ray Spectrom. 2013;42:262-7.

[76] Fernandez-Ruiz R, Garcia-Heras M. Analysis of archeological ceramics by total reflection X-ray fluorescence: quantitative approaches. Spectrochim Acta. 2008;B63:975-9.

[77] Fernandez-Ruiz R, Cabello Galisteo F, Larese C, Lopez-Granados M, Mariscal R, Fierro ]L. TXRF analysis of aged three way catalysts. Analyst. 2006;131:590-4.

[78] Nowak S, Winter M. Elemental analysis of lithium ion batteries. ] Atomic Anal Spectrom. 2017:32:1833-47.

[79] Kasnatscheew ], Evertz M, Streipert B, Wagner R, Nowak S, Laskovic IC, et al. Changing established belief on capacity fade mechanisms: thorough investigation of $\mathrm{LiNi}_{1 / 3} \mathrm{Co}_{1 / 3} \mathrm{Mn}_{1 / 3} \mathrm{O}_{2}$ (NCMIII) under high voltage conditions. J Phys Chem. 2017;C121:1521-9. DOI: 10.102/acs.jpcc.6b11746

[80] Evertz M, Kroeger T-N, Winter M, Nowak S. Total reflection X-ray fluorescence in the field of lithium ion batteries- Elemental detection in lithium containing electrolytes using nanoliter droplets. Spectrochim Acta. 2018;B149:118-23.

[81] Regadio M, Riano S, Binnemans K, van der Hoogenstraete T. Direct analysis of metal ions in solutions with high salt concentrations by total reflection X-ray fluorescence. Anal Chem. 2017;89:4595-603.

[82] Dhara S, Sanjay SK, Misra NL. TXRF determination of indium at ultra-trace levels in heavy water using In K $\alpha$ as analytical line and continuum excitation. J Radioanal Nucl Chem. 2015;306:231-5.

[83] Van der Hoogenstraete T, Jamar S, Wellens S, Binnemans K. Determination of halide impurities in ionic liquids by total reflection X-ray fluorescence spectrometry. Anal Chem. 2014;86:3931-8.

[84] De la Calle I, Quade M, Krugmann T, Fittschen UA. Determination of residual metal concentration in metallurgical slag after acid extraction using total reflection X-ray fluorescence spectrometry. X-ray Spectrom. 2014;43:345-52.

[85] Antosz F], Xiang Y, Diaz AR, Jensen A]. The use of total reflectance X-ray fluorescence for the determination of metals in the pharmaceutical industry. ] Pharm Biomed Anal. 2012;62:17-22.

[86] Shaw B], Semin D], Rider ME, Beebe MR. Applicability of total reflection X-ray fluorescence (TXRF) as a screening platform for pharmaceutical inorganic impurity analysis. ] Pharm Biomed Anal. 2012;63:151-9.

[87] Polignaro ML, Borionetti G, Galbiati A, Grasso S, Mica I, Nutsch A. Comparison of techniques for detecting metal contamination in silicon wafers. Spectrochim Acta. 2018;B149:313-21.

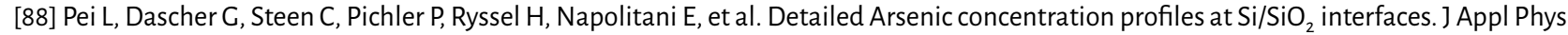
2008;104:043507.

[89] Krzyzanowska H, von Bohlen A, Klockenkämper R. Depth profiles of shallow implanted layers by soft ion sputtering and total reflection X-ray fluorescence. Spectrochim Acta. 2003;B58:2059-67.

[90] Steen C, Martinez-Limia A, Pichler P, Ryssel H, Pau; S, Lerch W, et al. Distribution and segregation of arsenic at the $\mathrm{SiO}_{2} / \mathrm{Si}_{\text {interface. ] }}$ Appl Phys. 2008;104:023518. DOI: 10.1063/1.2956700.

[91] Sekowski M, Steen C, Nutsch A, Birnbaum E, Burenkov A, Pichler P. Total reflection X-ray fluorescence as a sensitive analysis method for the investigation of sputtering processes. Spectrochim Acta. 2008;B63:1382-6.

[92] Lee JS, Lim HB. Thickness monitoring of sub-nanometer scale $\mathrm{La}_{2} \mathrm{O}_{3}$ films using total X-ray reflection spectrometry. ] Anal Atom Spectrom. 2009;24:1681-3. 
[93] Prange A, Reus U, Schwenke H, Knoth ]. Optimization of TXRF measurements by variable incident angles. Spectrochim Acta. 1999;B54:1505-11.

[94] Ingerle D, Meirer F, Pepponi C, Demenev E, Giubertoni D, Wobrauschek P, et al. Combined evaluation of grazing incidence X-ray fluorescence and X-ray reflectivity data improved profiling of ultra-shallow depth distribution. Spectrochim Acta. 2014;B99:121-8.

[95] Pepponi G, Guibertoni D, Bersani M, Meirer F, Ingerle D, Steinhauser G, et al. Grazing incidence X-ray fluorescence and secondary ion mass spectrometry combined approach for the characterization of ultrashallow arsenic distribution in silicon. J Vac Sci Technol. 2010;B28:C1C59.

[96] Brücher M, von Bohlen A, Becker M, Hergenroeder R. Investigation of nanoscale element distributions at surfaces with grazing incidence $X$-ray spectroscopy techniques- an instrumentation study. X-ray Spectrom. 2014;43:269-77.

[97] Frost MR, French M, Harris W. Application of TXRF for ion implantation dose matching experiments. Appl Surf Sci. 2004;231-232:734-7.

[98] Weiss C, Knoth ], Schwenke H, Ceisler H, Lerche ], Schulz R, et al. Potential of total reflection and grazing incidence XRF for contamination and process control in semiconductor fabrication. Mikrochim Acta. 2000;133:65-8.

[99] Schwenke H, Knoth ], Fabry L, Pahlke S, Scholz R, Frey L. Measurement of shallow arsenic impurity profiles in semiconductor silicon using time-of-flight secondary ion mass spectrometry and total reflection X-ray fluorescence spectrometry. ] Electrochem Soc. 1997;144:397983.

[100] Yamada T, Takahara H, Ohbuchi A, Matsuda W, Shimizu Y. Observation of Au-Cu alloying by grazing incidence X-ray fluorescence. Spectrochim Acta. 2018;B149:256-60.

[101] Mori Y, Uemara K, lizuka Y. Whole surface analysis of semiconductor wafers by accumulating short-time mapping data of total reflection X-ray fluorescence spectrometry. Anal Chem. 2002;74:1104-10.

[102] Klockenkämper R, von Bohlen A. A new method for depth-profiling of shallow layers in silicon wafers by repeated chemical etching and total reflection X-ray fluorescence analysis. Spectrochim Acta. 1999;B54:1385-92.

[103] Wiener G, Michaelsen C, Knoth ], Schwenke H, Bormann R. Concentration-depth profiling using total reflection X-ray fluorescence spectrometry in combination with ion-beam microsectioning techniques. Rev Sci Instrum. 1995;66:20-4.

[104] Schwenke H, Knoth ], Günther R, Wiener G, Bormann R. Depth profiling using total reflection X-ray fluorescence spectrometry alone and in combination with ion beam sputtering. Spectrochim Acta. 1997a;B52:795-803.

[105] Brennan S, Ishii HA, Luening K, Pianetta P, Burnett DS. Synchrotron total-reflection X-ray fluorescence (SR-TXRF) of Cenesis return samples. Lunar Planet Sci. 2006;XXXVII:2029.

[106] Steeves-Lloyd K, Bolotin IL, Schmeling M, Hanley L, Veryovkin IV. Metal impurity assisted formation of nanocone arrays on Si by low energy ion-beam irradiation. Surf Sci. 2016;652:334-43.

[107] Schmeling M, Burnett DS, Jurewicz A], Veryovkin IV. Steps towards accurate large area analyzes of Cenesis solar wind samples: evaluation of surface cleaning methods using total reflection X-ray fluorescence spectrometry. Powder Diffr. 2012;27:75-8.

[108] Müller M, Hoenicke P, Detlefs B, Fleischmann C. Characterization of high-k nanolayers by grazing incidence X-ray fluorescence spectrometry. Materials. 2014;7:3147-59.

[109] Choi Y, Eng P], Stubbs ]E, Sutton SR, Schmeling M, Veryovkin IV, et al. Discrimination and quantification of Cenesis implanted solar wind $\mathrm{Fe}$ and $\mathrm{Ni}$ abundances using $\mathrm{X}$-ray standing wave fluorescence yield depth profiling with internal referencing. Chem Ceol. 2016;441:246-55.

[110] Pianetta P, Singh A, Luening K, Brennan S, Homma T, Kubo N, et al. Characterization of silicon wafer surfaces with SR-TXRF. The Rigaku J. 2003;19/20:36-44.

[111] Caby B, Brigidi F, Ingerle D, Nolot E, Pepponi C, Streli C, et al. Study of annealing induced interdiffusion in $\operatorname{In}_{2} \mathrm{O}_{3} / \mathrm{Ag} / \mathrm{In}_{2} \mathrm{O}_{3}$ structures by a combined X-ray reflectivity and grazing incidence X-ray fluorescence analysis. Spectrochim Acta. 2015;B113:132-7.

[112] Hoenicke P, Beckhoff B, Kolbe M, Giubertoni D, van Den Berg ], Pepponi G. Depth profile characterization of ultrashallow junction implants. Anal Bioanal Chem. 2010;396:2825-32.

[113] Hoenicke P, Kraemer M, LuehI L, Andrianov K, Beckhoff B, Dietsch R, et al. Development and characterization of sub-monolayer coatings as novel calibration samples for $X$-ray spectroscopy. Spectrochim Acta. 2018;B145:36-42.

[114] Kayser Y, Szlachetko ], Banas D, Cao W, Dousse JC, Hoszowska ], et al. High energy-resolution grazing emission X-ray fluorescence applied to the characterization of thin films on Si. Spectrochim Acta. 2013;B88:136-49.

[115] Korytowski A, Abuillan W, Makky A, Konovalov O, Tanaka M. Impact of lipid oxidation on vertical structures and electrostatics od phospholipid monolayers revealed by combination of specular X-ray reflectivity and grazing X-ray fluorescence. J Phys Chem. 2015;119:978794.

[116] Nolot E, Caby B, Gassiloud R, Veilerot M, Eichert D. X-ray reflectometry and grazing-incidence X-ray fluorescence characterization of innovative electrodes for tantalum-based resistive random access memories. Spectrochim Acta. 2018;B149:71-5.

[117] Nowak SH, Banas D, Blchuki W, Cao W, Dousse ]-C, Hoenicke P, et al. Grazing X-ray fluorescence from periodic structures on silicon and silica surfaces. Spectrochim Acta. 2014;B98:65-75.

[118] Pessoa W, Roule A, Nolot E, Mazel Y, Bernard M, Lepy M-C, et al. Grazing incident X-ray fluorescence combined with X-ray reflectometry metrology protocol of telluride-based films using in-lab and synchrotron instruments. Spectrochim Acta. 2018;B149:143-9.

[119] Pollakowski B, Beckhoff B. Nanostructure speciation depth profiling of complex TiOx nanolayer structures by a combined X-ray reflectivity and grazing incidence X-ray fluorescence analysis. Spectrochim Acta. 2015;B113:132-7.

[120] Rotella H, Caby B, Menesguen Y, Mazel Y, Valla A, Ingerle D, et al. Elemental depth profiling in transparent conducting oxide thin films by X-ray reflectivity and grazing incident $X$-ray fluorescence combined analysis. Spectrochimica Aca. 2017;B135:22-8.

[121] Das G, Khooha A, Singh AK, Tiwari MK. Probing nanostructures materials using X-ray fluorescence analysis. X-ray Spectrom. 2017;46:448-53.

[122] Almeida DS, Santos RS, Anjos M], Ferreira ST, Souza AS, Lopes RT. Multi element concentration analysis of Swiss mice brains on experimental model of Alzheimer's disease induced by beta-amyloid oligomeres. X-ray Spectrom. 2017;46:397-402. 